$$
\begin{aligned}
& L E 3 \beta 7 \\
& 1950 A 8 \\
& L=R 2 \\
& C \text { Co. }
\end{aligned}
$$

\title{
RADIOCHEMICAL STUDIES On GRAPHITE FERRIC CHLORIDE
}

BY

\author{
ROBERT MART IN LAZO
}

A Thesis Submitted in Partial

Fulfilment of the Requirements

for the Degree of

$$
\text { MASTER of ARTS }
$$

in the

DEPARTMENT Of CHEMISTRY

The University of British Columbia.

April 1950.

$$
\begin{aligned}
& \text { Qccepted by the Department } \\
& \text { of Chemistry on Sury 2,1950 }
\end{aligned}
$$




\section{ABSTRACT}

Graphite ferric chloride, $\mathrm{C}_{12} \mathrm{FeCl}_{3}$, was prepared by heating anhydrous ferric chloride with graphite at $305^{\circ} \mathrm{C}$. The purified compound containing 53\% ferric chloride was not attacked by hot $6 \mathrm{~N}$ hydrochloric acid or $6 \mathrm{~N}$ sodium hydroxide solutions. X-ray diffraction measurements gave a powder pattern which was distinctly different from that of e ither graphite or ferric chloride and from which it was apparent that no free ferric chloride existed in the compound. The separation of the graphite layer-planes was increased from 3.36 to $9.4 \AA$ by the intercalation of the ferric chloride molecules. Tests for exchange between $\mathrm{C}_{2} \mathrm{FeCl}_{3}$ and $\mathrm{Fe}^{+++}$ion were made using radioactive $\mathrm{Fe} 59$. In no instance was any measurable exchange observed. The compound was subjected to neutron irradiation and the Szilard-Chalmers yield of separable activity calculated and identified. The separated portion contained less than $1 \%$ of the total activity and consisted of $\mathrm{Fe}^{59}, \mathrm{P}^{32}$ and $\mathrm{s}^{35}$, free of detectable radiation decomposition products. The active Fe portion was separated by ether extraction.

The lack of exchange and the low Szilard-Chalmers yield are both attributed to the formidable steric hindrance effects which result from the configuration of the "stacked layers" structure for graphite ferric chloride. 


\section{ACKNOWLEDGEMENTS}

I wish to express my gratitude to Dr. J.G. Hooley who so ably directed this research project.

Appreciation is also expressed to the National Research Councll of Canada for the summer research scholarship awarded the author during the course of this study, and to the British Columbia Research Council who so kindly permitted the use of their X-ray spectrometer. 


\section{TABIE of CONTENTS.}

\section{Introduction}

1. Graphite and Graphite Compounds............ I

A.) Graphite Ferric Chloride............. 9

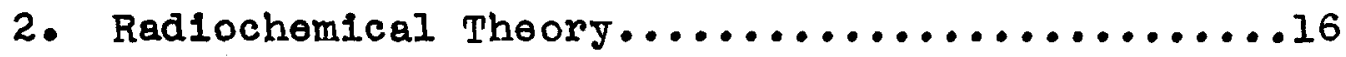

A.) Isotop1c Exchange Reactions............18

B.) The Szilard-Chalmers Reaction

in the Chain Reacting Pile.......26

3. Radiochemical Techniques...................33

Experimental Results

1. Preparation of Graphite Ferric Chlorido

$\left[\mathrm{C}_{12} \mathrm{FeCl}_{3}\right]_{\mathrm{n}} \ldots \ldots \ldots \ldots \ldots \ldots \ldots \ldots \ldots \ldots \ldots$

2. Tests for Exchange betwoen Graphite Ferric

Chloride and Ferric lon, using

Radioactive $\mathrm{F}^{59} \ldots \ldots \ldots \ldots \ldots$

3. The Szilard Chalmers Reaction with Graphite

Ferric chloride..............56

Discussion of Results.......................63

Suggest1ons for Future Research.................66

Blbllography............................67 


\section{Radiochemical Studies on Graphite Ferric Chloride.}

\section{INTRODUCTION}

Carbon itself is a refractory, non-volatile, insoluble solid, and gives rise to lamellar compounds which are insoluble, non-volatile and often unstable solids about which classical chomical methods give very littlo information. $X-$ ray studies have proved particularly fruitful, and most of the information concerning the structure of solid carbon, and Its lamellar compounds has been determined from $X$-ray diffraction measurements.

Carbon, in the form of diamond, belonging to the cubic system, was one of the earliest crystals to be investigated by X-rays(2). The essential point of the space lattice structure for diamond, is that every atom of carbon is surrounded by four other atoms situated at the corners of a regular tetrahedron. The distance between the centers of two adjolning atoms is $1.54 \AA$, which corresponds very closeig to the distance between two carbon atoms attached to each other by a single covalent bond in aliphatic organic compounds. This agreement, together with the fact that each carbon atom in diamond has four others situated round it at the corners of a regular tetrahedron, suggests that every atom is joined to four others by covalent linkages. A diamond crystal may then, be regarded as a macromolecule of carbon. Its hardness can be ascribed to the strength of the chemical bonding of the atoms and its uniformity in all directions throughout the crystal. 
The physical properties of the other allotropic form of carbon $v 1 z \cdot$, graphite, of the hexagonal system, are quite different from those of diamond. These differences are found to correspond to important changes in the internal structure of the crystal.

Although graphite is so obviously crystalline, its opaque cha racter and the rarity of well developed crystals restrict considera bly the crystallographic information which can be obtained by optica 1 methods. The lattice s tructure which first recelved wide acceptance was deduced in 1924 by J.D. Bernal (I) and confirmed by C. Mauguin $(1926) \div(12)$ and by H. Ott (1928) (16).

The carbon atoms are arranged in flat layers each having hexagonal honeycomb-like structure. These are stacked parallel to each other in such a way that half the atoms in one layer lie normally above half the a toms in the layer beneath. Alternate layers $11 \theta$, atom for atom mormally above each other. The carbon atoms in the layers are spaced center to center at a distance of $1.415 \AA$ compared with a spacing of $1.54 \AA$ in the diamond lattice. The spacing between adjacent layer-planes of graphite is $3.36 \AA$. The carbon atoms within the layer-planes therefore are bonded together by powerful covalent valency forces, more powerful tha $\mathrm{n}$ those in the dlamond. The four valences of each carbon atom are used to form bonds with its three neighbors, and the glant layser molecule resonates among many va lence-bond structures in such a way that each carbon-carbon bond ochieves one-third double-bond character. 
This arrangement corresponds very closely to the six-membered rings formed in benzene, naphthalene and other aromatic hydrocarbons. Indeed, in his review of recent work on the similiarity of the graphite electron structure with that of aromatic compounds (6), Hofmann has stated, "No sharp boundary is found. The intermediary stages of graphite nuclel in coal and in various charcoa is constitute gradual cha ngo from aromatic compound to crystalline graphite". However the resonance system in the graphite layer-planes is so degenerate that odd electrons behave more like metallic electrons and account for the electronic conductivity of graphite, which with corta in pure specimens is twice that of mercury. The electrical conductivity in a direction parallel to the layer-planes is much greater than in a direction at right angles to it.

The hexagona 1 lajers of carbon molecules are separated by a distance so large $(3.36 \AA)$ that there can be no covalent bonds between them, and the superimposed layer molecules are held together only by weak van der Waals forces (17). The layer-lattice set up for graphlte accounts for the cleavage which occurs so easily between the separate layer-planes in the crystal, and the use of graphite as a lubricant depends on this ablilty of one plane of atoms to slide easily over another. 

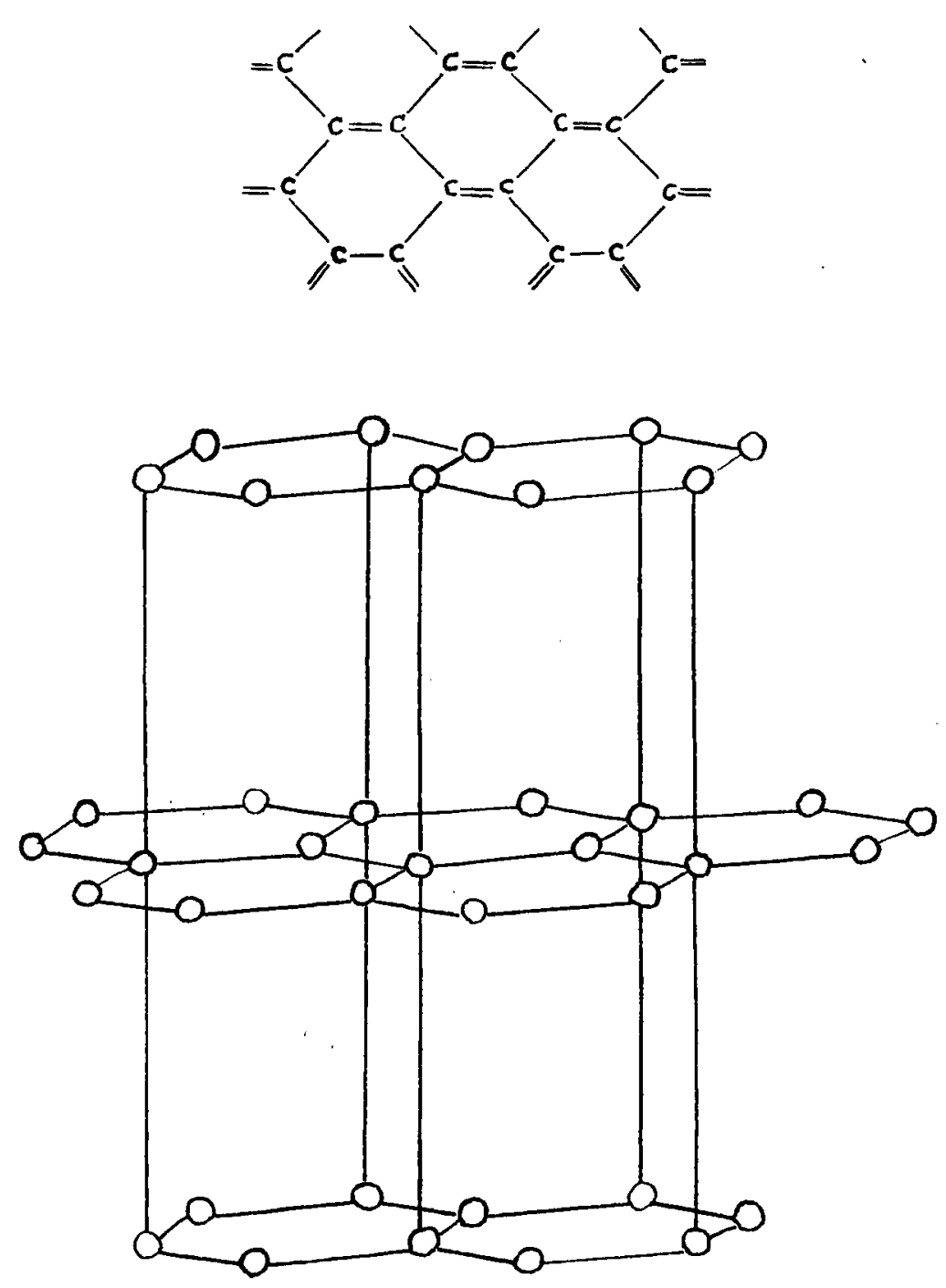

Figure 1. The arrangement of carbon atoms in the graphite crystal. 
The structure of the graphite crystal lattice appeared to be definitely established until D.S. Laidler and A. Taylor (10) in 1940 pointed out that this structure does not account for some faint lines which occur in the $X-r a y$ powder photographs of many specimens of Eraphite. Another form of graphite prosent to about $10 \%$ is suggested. Instead of the alternate planes being normally above one another, a third plene is inserted which is symmetrically related to the planes above and below.
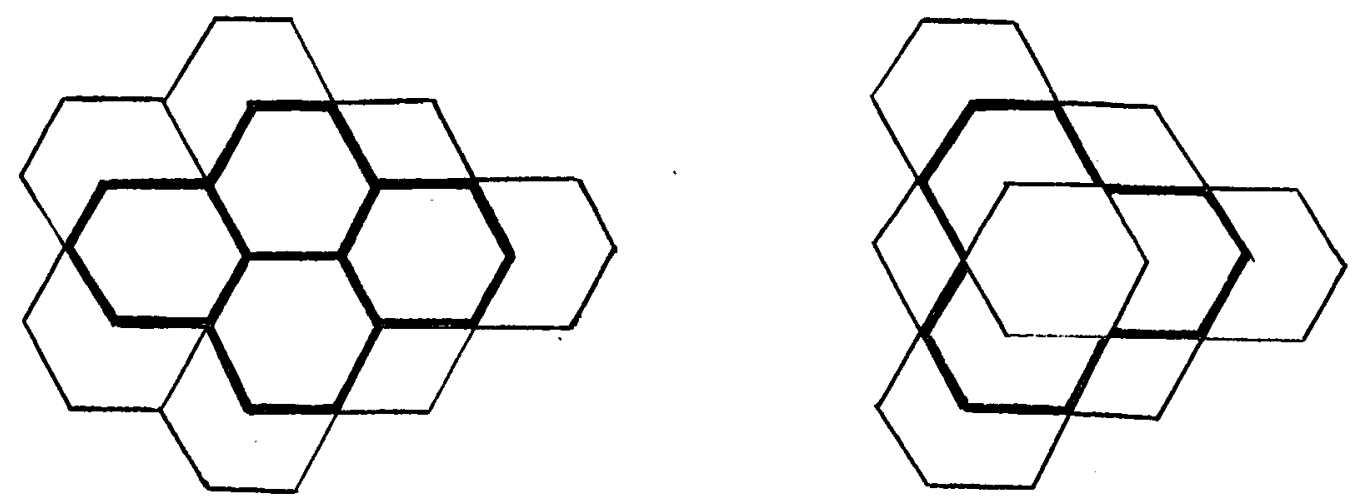

Figure 2. The two ways of stacking the hexagon layer-planes in the graphite lattice.

The graphite lattice structure with its powerful covalent bonds within the layer-planes and the relatively weak bonding forces between the layer-planes offers an explanation of 
the interesting anisotropic properties both physical and chemical, associated with graphite crystals. Observations on the swelling of graphite electrodes and the intumescence of graphite, led to the discovery that certain molecules and/or Ions could penetrate between the layer-planes of the graphite lattice to form more or less stable structures. This swelling, es pointed out by H. Thiele (33), occurs with highly crystalline forms of graphite and occurs exclusively along the $C$ axis of the hexagonal flake.

Graphite salts: The action of concentrated acids in the presence of a suitable oxidizing agent, has been shown to bring about the formation of blue graphite salts (7) (23). Each hexagon layer-plane becomes a macro positive ion with a charge equal and opposite to the number of negative ions bonded to 1t. When graphite is treated with boiling sulfurlc acid in the presence of a few drops of nitric acid, the iridescent blue graphite bisulfate results.

$$
\text { Graph1te }+\mathrm{nH}_{2} \mathrm{SO}_{4}+\mathrm{n} / 2 \mathrm{O} \rightarrow \text { Graphite }^{n+}\left(\mathrm{HSO}_{4}^{-}\right) \mathrm{n}+\frac{n}{2} \mathrm{H}_{2} \mathrm{O}
$$

The compound containing the maximum amount of intercalated b1sulfa te fon and sulfuric acid corresponds to the idealized stiochiometric composition $\mathrm{C}_{24} \mathrm{HSO}_{4} \cdot 2 \mathrm{H}_{2} \mathrm{SO}_{4}$. The addition of a small quantity of water to the sulfuric acid, even from exposure of the acid to the atmosphere brings about the decomposition of the blue graphite into the original graphite. X-ray examination of a specimen of graphite bisulfate suspended in pyrophosphoric acid 
showed that the intercalation of the sulfuric a cid had Increased the inter layer-plane spacing of the graphite from $3.36 \AA$ to $7.98 \AA(19)$.

Besides the bisulfate, graphite forms other similar compounds. H.L. Riley, in his review of "Lamellar compounds of carbon" (19) describes the graphite saits nitrate, perchlorate, biselenate, phosphate, pyrophospha te and arsenate, all prepared and characterized by Rlldorff and Hofmann (23).

Graphite Monofluoride: (27) Graphite combines with fluorine at one atmosphere pressure and a temperature of $420^{\circ} \mathrm{C}$. to form a grey hydrophobic solid the composition of which is $(C F)_{n}$ - The constant composition, the grey color and the low electrical conductivity, which is only one-hundred-thousandth that of graphite, all suggest that graphite mono- fluoride is a chemical campound. The fluorine atoms are arranged in six parallel planes between each pair of carbon layerpla nes which a re spgced at $8.17 \AA$ - Rlldorff has recently announced the preparation of a new graphite-fluorine compound (24) tetracarbon monofluoride $\left(\mathrm{C}_{4} F\right)_{n}$. The compound is not a ttacked by dilute acids or alkali even on heating although concentrated sulfuric acid above $100^{\circ} \mathrm{C}$ slowly decomposes it.

Brom-graphite: A pecular bromine adsorption complex of graphite has been produced (2I) by shaking a suspension of graphite in cold concentrated sulfuric acid with bromine. The graphite samples will take up roughly one atom of 
bromine to each eight atoms of carbon and give it up again completely on standing in the air. The X-ray analysis of brom-graphite showed a carbon layer-plane spacing of $7.05 \AA$.

Alkali-graphite: When graphite is heated with potassium, rubidium or cesium in an evacuated tube, a blue-black alkali-graphite compound is produced. Shaking the compound in mercury converts it to graphite. It was also found that the adsorption of potassium vapor occured in a stepwise manner, indicating the formation of more than one compound. Schleede and Wellmann (28) determined from X-ray studies that for the $C_{B} K$ compound, each potassium atom lay normally over the center of every second carbon atom hexagon of the basal planes. $C_{16} K$ has a layer of potassium atoms in every second inter-layer-plane space in the graphite lattice. These substances were shown to be quite different from ordinary alkali metal carbides because only hydrogen and no trace of hydrocarbon was evolved when they reacted with water. The heat of formation of $C_{8} \mathrm{~K}$ or $\mathrm{C}_{16} \mathrm{~K}$ using excess potassium, was determined to be about $1500 \mathrm{cal} / \mathrm{gm}$. atom of carbon (4).

Graphit1c oxide: Samples of graphitic oxide have been prepared by treating graphite that had been previously washed with hydrochloric ac1d, with concentrated sulfuric acid and nitric acid in the presence of potassium chlorate (26). After the product has been dried under vacuum over potassium pentoxide the acid groups can be determined by methylation 
and acetylation. However, in no case has a fixed stiochiometrical relationship been found, as analyses for $0: 0$ varies between $6: 1$ and $6: 2.5$. Further studies of the crystal structure have indicated that the carbon layers display a hydroaromatic character.

It is interesting to note the close parallelism between the chemistry of the graphite compounds that have been mentioned and that of the triarylmethyls (18). This is indicated by the existence of the graphite salts, graphite monofluoride, the alkall graphites and graphite oxide, all of which appear to be definite compounds. The triarylmethyls also form alkali salts, halides and peroxides and in general show the same amphoteric properties as do the hexagon layer-planes of the graphite crystal lattice. This is not surprising, for considering one carbon atom in a layer-plane, it will be seen that its three valency bonds are connocted each to an aromatic grouping of carbon atoms and that these three bonds are co-planar, like those in triphenylmethyl. The stability of the triphenylmethyl free radical has been expla Ined by assuming that the odd electron on the central carbon a tom resonates among many of the aromatic carbon atoms in the molecule. This is a very similar type of resonance to that occuring in graphite.

\section{A. Graphite ferric chloride:}

Perhaps the most interesting of the graphite compounds reported to date, is the surprisingly sta ble graphite ferric chloride, which appens to fall into a 
different category, as no similar compound is formed by the triarylmethyls.

Graphite ferric chloride was prepared and characterized by $W_{0}$ Rudorff and H. Schulz (25) in 1940 and is reviewed in the U. S. publication F.I.A.T. (1948) (22).

When graphite is heated to $200^{\circ} \mathrm{C}$, and above with two or three times its own weight of anhydrous ferric chloride in a sealed tube, the amount of free ferric chloride decreases. The ferric chloride which does not react can be sublimed off or extracted in dilute acid solutions, leaving an apparently homogeneous green to matt black reaction product which has increased in weight up to $200 \%$ of the weight of the original graphite.

Specimens prepared between $180^{\circ}$ and $300^{\circ} \mathrm{C}$. contain between $72 \%$ and $60 \%$ of ferric chloride, which is equivalent to $1 \mathrm{FeCl}$ : 5.5-9 C atoms. Using reaction temperatures between $325^{\circ}$ and $400^{\circ} \mathrm{C}$, the ferric chloride content falls to between $37 \%$ and $31 \%$ i.e. $1 \mathrm{FeCl}: 23-29 \mathrm{C}$ atoms, and between $400^{\circ}$ and $500^{\circ} \mathrm{C}$. the product contains only $5 \%$ ferric chloride. This is completely expelled only at a temperature above $500^{\circ} \mathrm{C}$.

At $309^{\circ} \mathrm{C}$. the graphite ferric chloride complex showed a pronounced intumescence accompanied by the evolution of $\mathrm{FeCl}_{3}$ vapour. This phenomenon was repeated again at $409^{\circ} \mathrm{C}$. and the re then remained a grey pulverulent substance which still contained about $5 \%$ ferric chloride.

Rlldorff and Schulz found that part of the ferric chloride could be extracted from the complex with water or dilute acids or with alcohol, ether, benzene, etc. When extracted in 
this way the graphite ferric chloride prepared below $309^{\circ} \mathrm{C}$. left a product containing about $56 \%$ ferric chloride no matter what solvent was employed and independently of the original graphite crystal form. This value of $56 \%$ ferric chloride corresponds to about one molecule of $\mathrm{FeCl}_{3}$ to ten $\mathrm{C}$ atoms. Treated in the same way a specimen prepared between 310 and 400 degrees centigrade gave a product containing $31 \%$ ferric chloride or one $\mathrm{FeCl}_{3}$ molecule to thirty $\mathrm{C}$ atoms. The ferric chloride remaining in the complex after the extraction was found to be extraordinarily unreactive and specimens of the compound were scarcely attacked by hot dilute acid or alkali. Reducing agents such as hydrazine and sulfurous acid were found to be without appreciable action. Oxidizing agents such as concentrated nitric acid or not concentrated sulfuric acid however, decomposed the complex.

The properties of graphite ferric chloride and the stepwise decrease in ferric chloride content, suggested the existence of two compounds and this was confirmed by $\mathrm{X}$-ray diffraction measurements. The powder photographs of specimens containing $56-72 \%$ ferric chloride showed pronounced differences from those of specimens containing $30-37 \%$ of the metallic salt. The diffraction patterns were all distinctly different from those of either graphite or ferric chloride. Rlldorff confirmed from $X$-ray diffraction measurements, that the spacing between the layer-planes in the graphite had been increased from 3.36 to $9.4 \AA$ by the penetration of ferric chloride molecules. This agreed with the increase in volume of a single crystal to about 2.5 times observed microscopically and from density measurements. 
It is known that anhydrous ferric cthloride crystallizes in a layer lattice. The iron lons form a regular hexagonal network above and below which there is a parallel triangular net plane of chloride ions. The dimensional requirements of these layer-planes along the $\mathrm{C}$ axis is about $5.8 \mathrm{~A}$. The question arises as to how far the limits of the ferric chloride content found by chemical analysis viz. I $\mathrm{FeCl}_{3}$ : 5.50 to $1 \mathrm{FeCl}_{3}$ : $9 \mathrm{C}$ can be correlated with the suggested crystal structure for graphite ferric chloride. Rlldorff states that this requires an upper limit of 1:6.02 for the $\mathrm{FeCl}_{3}: \mathrm{C}$ ratio, and that somewhat higher value is due possIbly to cap1llary condensation. The compound with the highest ferric chloride content probably has a hexagonal packing of the ferric lons, and when the excess of ferric chloride is removed by washing the ferric ions take up a triangular packing 1.e. one in which alternate ferric ions have been eliminated from the hexagonal arrangement. In the limiting case with the removal-of half the ferric lons to form the triangular arrangement, the ratio of $\mathrm{FeCl}_{3}: \mathrm{C}$ would become 1:12.04. In the work done by Rlldorff and Schulz in 1940, the rat10 of $1: 10.4$ was reported for washed specimens of graphite ferric chloride. One sample after being bolled with $10 \% \mathrm{H}_{2} \mathrm{SO}_{4}$ for twenty-four hours gave the ratio 11.9. vapour pressure measurements indicated that the ferric chloride taken up by the graphite in excess of about 56\% was loosely bound and probably only served, to fill holes in the large mesh network of the more firmly bound ferric chloride molecules. 


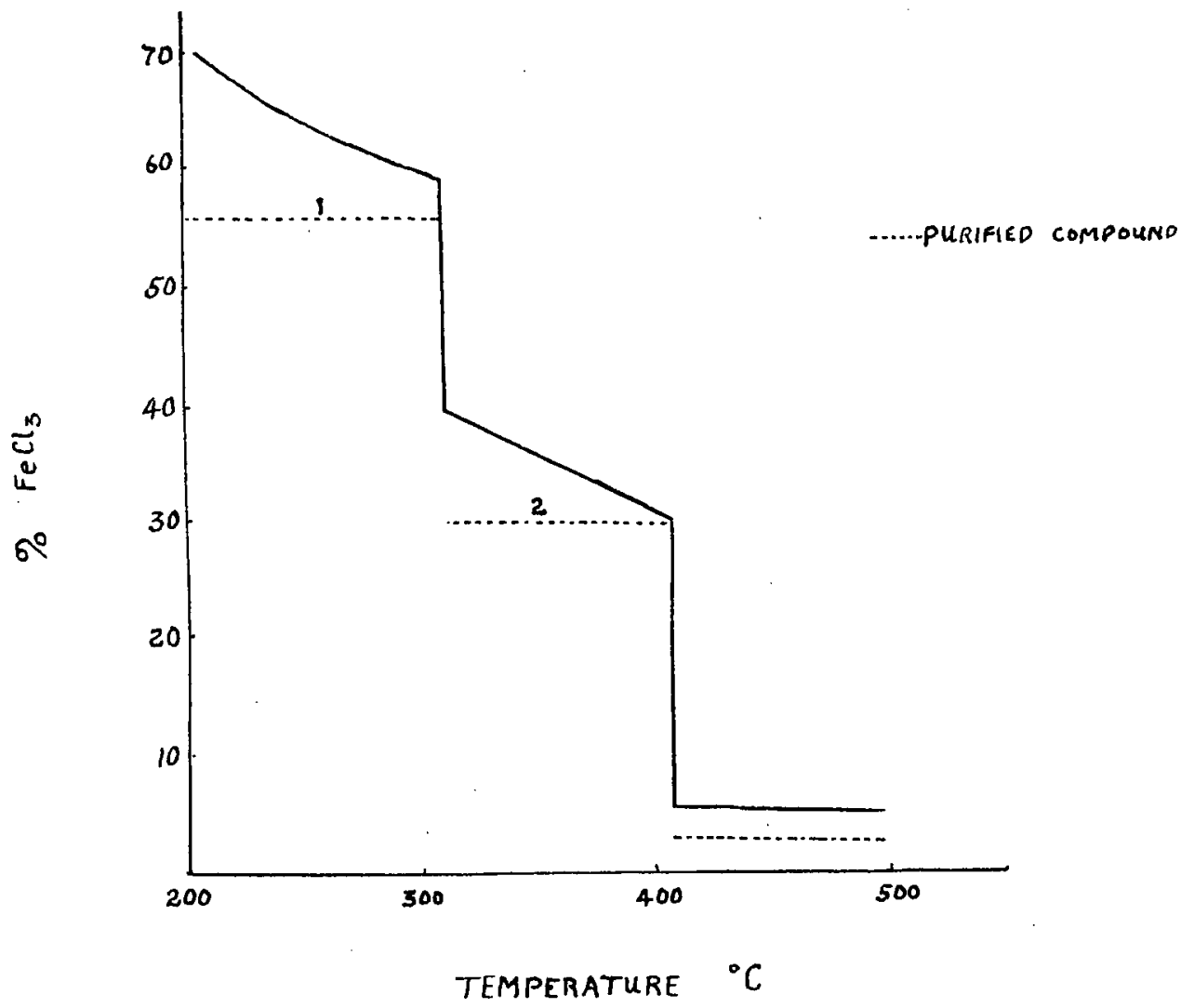

Figure 3-

The effect of temperature on Graphite ferric chloride.

Figure 3. shows the change in the amount of intercalated ferrio chloride with temperature, as illustrated by Rthdorff. In the compound prepared below $309^{\circ} \mathrm{C}$. the ferric chloride has penetrated hetween all. the layer-planes of the graphite lattice. When this compound is heated to $309^{\circ} \mathrm{C}$. and above there is a sudden evolution of ferric chloride as these molecules are forced from between every alternate pair of layeroplanes of graphite. The dotted lines represent the purified compounds, 1) with ferric chloride botween a 11 the graphite layer-planes, and 2) with the intercala tion of ferric chloride only betwen every 
second pair of layer-planes. It will be noted that between 200 and $309^{\circ} \mathrm{C}$. temperature has no effect on the percentage of ferric chloride hela by the graphite in the purified fully intercalated compound. The same is true for the second compound between the temperature of 309 and $409^{\circ} \mathrm{C}$. Above $409^{\circ}$ the percentage of ferric chloride drops again leaving only about 5\%. Figure 4. shows the layer-plane sequence of the two compounds.
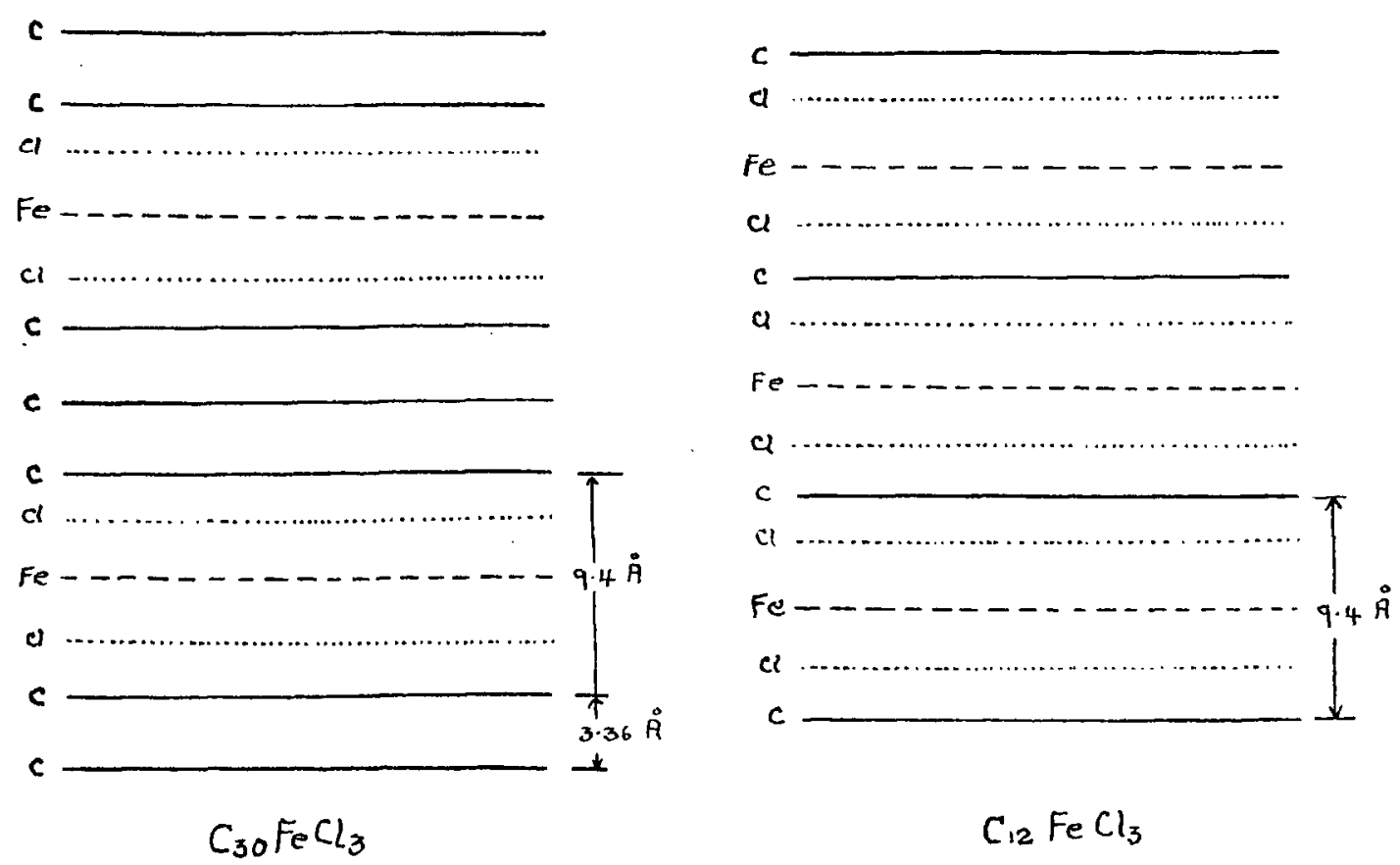

$$
\mathrm{C}_{12} \mathrm{FeCl}_{3}
$$

\section{Figure 4-}

The layer-plane sequence of Graphite ferric chloride.

The particular stability of the graphite ferric chloride compounds has necessitated some explanation of the type of bonding they exhibit. As has been mentioned previously, the strongly bonded carbon atom layer-planes 
of the graphite lattice are held together only by woak van der Waals forces. The extreme inactivity exhibited by graphite ferric chloride, in which the graphite layerplanes have been separatea from 3.36 to $9.4 \AA$, makes it seem quite unlikely that the bonding of the ferric chloride In the compound is of the same type. Rlldorff has found that the magnetic moment of the $\mathrm{F}^{+++}$ions in the compound is the same as that of pest in $\mathrm{FeCl}_{3}$ and concludes that oovalent bonding of the $F e-C$ type is out of the question (22). He suggests instead, that there is a polarization of the conductivity elactrons of the carbon layer-planes toward the central layer of iron atoms but that these remain essentially ionic. one can then imagine some degree of electrovalent bonding of the chlorine ions to the macro positive ion layer-planes.

In view of the nature of the bonding of the ferric ions and the configuration of atoms about thom in the graphite ferric chloride structure, it seomed that an investigation of the possibility of exchanging these ions or of ejecting them from the lattice by szilard chalmers reaction, would be of interest and perhaps further elucidate the structure of the compound. 
2. RADIOCHEMICAL THEORY

Nuclear chemistry is a field of activity as old as nuclear physics. The workers in the late nineties made studies of the possible influence of chemical binding on radioactive decay and searched among the elements for those displaying radioactiveproperties, with the result that a number of new elements were discovered, existing only in radioactive forms. Nuclear science remained predominantly in the hands of physicists, however, in spite of the vast chemical implications of developments in nuclear transmutation and artificial radioactivity that had made available radioactive forms of all of the chemical elements.

With the developments in "modern alchemy", born with the emergence of the uranium chain-reacting pile, chemists of the world began to play a more prominent role in nuclear research. Today nuclear chemistry has achieved greater importance as a part of chemical science, rather than as an operational appendage of nuclear physics. The basic principles of radiochemistry have been well. worked out on the na turally occuring radioactive elements by such ploneers as Hepesy, Paneth, Fajans, Hahn and others (5). With the extension of radiochemical techniques to all the elements, the field of radiochemistry expanded tremendously as chemists hastened to make use of this powerful new tool for research. The voluminous literature that has been compiled on radiochemical work 
necessitates that this discussion be confined to only the particularly relevant topics of exchange reactions and the szilard-Chalmers reaction. 


\section{A. Isotopic Exchange Reactions.}

Since artificially produced radioactive isotopes have become readily avaliable to scientific worliers, a great deal of information concerning the nature of chemical Iinkages and the mechanism of reactions has been obtained from a study of the exchange of isotopic atoms. The literature of such researches has become quite voluminous and it is not within the realm of this paper to more than mention some general considerations.

The kinetic mechanisms operating in systems at equilibrium or in the steady state can be studied directly by the use of isotopic labeling techniques. In typical experiments on isotopic exchange all participating molecular species are in elementic equilibrium and the overall. chomical composition of the system is maintained invariant throughout the experimental period. One or more of the reacting molecules is labellad by incorporation of a radioactive isotope of a constituent atom and observations are made on the rate at which isotopic equilibration is attained. The rate law for isotopic exchange reactions is first-order in the concentration of isotopic-label.lod molecules (15). This generalization is a consequence of the requirement that the overall chemical composition of the reacting system be maintained invariant. Thus, suppose the exchange raaction to bo written in the form

$$
\mathrm{AX}+\mathrm{BX}^{\prime} \rightleftarrows \mathrm{AX}^{+}+\mathrm{BX}
$$

where the prime symol refers to the isotopically labelled 
atom. In such a reaction, there must exist some reversible mechanism whereby the atomic partners are enabled to exchange positions in the molecules AX and BX. Suppose this mechanism dictates a rate of exchange $R$ which is any function of the thermodynamic concentrations and a system variable such as temperature. Then, the first-order law for the exchange of isotope is

$$
\frac{d x}{d t}=R\left(\frac{y}{b}-\frac{x}{a}\right)
$$

where a is the concentration in moles per litre of moleculeg $(A X)+\left(A X^{\prime}\right)$, $b$ the concentration of molecules $(B X)+\left(B X^{\prime}\right), X$ the concentration of isotopic molecules ( $A X^{\prime}$ ) and $y$, the concentration of isotopic molecules (BX'). The generalized equation involving polyatomic types $\mathrm{AX}_{n}$ will be amenable to the same treatment if the concentration of the reacting species are expressed in gram atoms per litre. This expression implies that, no matter what the overall rate of exchange reaction may be, the rate of appearance of labelled isotopes in the molecules initially unlabelled follows a first-order law.

From equation (2) it is easy to show that

$$
R t=-\frac{(a)(b)}{(a)+(b)} \ln \left(1-x / x_{\infty}\right)
$$

where $t$ is the $t$ ime and $x_{\infty}$ is the concentration of isotope In $\mathrm{AX}$ at equilibrium.

The requirements for an isotopic exchange then are, (1) the existence of some reversible equilibrium whereby the reacting molecular species may consummate the exchange, 
and (2) that no isotopic differentiation can occur. It is important also to note that side reactions due to radiation effects should bo taken care of in control experiments at different radiation levels.

A great number of experiments have been carried out by various workers seeking correspondences between types of chemical bonding and the kinetics of isotopic exchange. It is of interest to mention some of these experiments here. The great mass of information gathered about the structure of molecules using methods based on $\mathrm{X}$-ray diffraction electron-diffraction, magnetic analysis, measurement of electric moments, band spectrum analysis, etc., has been remarkably well correlated and systematized in terms of the classification of chemica 1 bonds into covalent,electrovalent and metallic types. Pauling has extended this classification of chomical bond type (17) using a quantum mechanical approach based on the additivity of bond energies calculated from atomic orbital theory.

To evaluate correlations between isotopic exchange date and bond type, one should neglect systems in which there exist obvious routes for exchange through ionic mechanisms. SJstems involving couples such as $\mathrm{Br}_{2} / \mathrm{Br}^{-}, \mathrm{Hg}^{++} /$ $\mathrm{Hg}_{2}^{++}, \mathrm{Fe}(\mathrm{CN})_{6}^{4-} / \mathrm{Fe}(\mathrm{CN}) 6^{3-}$ etc., have been observed to exhibit rapid exchange through electron transfer, either through an Ionlzation mechanism or through an intermediate complex. However, useful information about such bonds is infrequently obtained from observations of exchange rates. 
other investigations involve systems for which reaction mechanisms involving bond splitting and dissociation equilibria other than those of ionization are requisite in producing exchange. Bonds between atoms in molecules participating in such exchanges were classified as "pure" covalent or electrovalent or as a mixture of these two extreme types, on the basis of non-isotopic techniques. Than the criterion based on rapidity of exchange was applied to ascertain whether any correspondence existed between degree of covalency and rate of exchange.

In crystall ine diphenyliodonium lodide it has been shown by X-ray anlysis (13) that two lodine bonds are covalent and one ionic. The $X$-ray data are consistunt with a scheme involving the two covalent bonds in the lodonlum Ion with the ionic bond between the iodonium ion and the iodide viz. $\left(\mathrm{C}_{6} \mathrm{H}_{5}\right)_{2} \mathrm{I}^{+}-\mathrm{I}^{-}$. When this substance is brought into aqueous solution in the presence of labelled $\mathrm{I}^{-}$and then recrystallized from solution, labellod iodine is found in the solid. This labelled iodine can be removed with. silver fon (as the hydroxide), the resulting $\left(\mathrm{C}_{6} \mathrm{H}_{5}\right)_{2} \mathrm{IOH}$ containing no la belled iodine. Furthermore no exchange can be detected between the two iodine atoms of the diphenylLodonium iodide itself (9).

It has been showm by J.F. Flagg, that in cobaltous cobalticyanide, there is no exchange between the cobalt atoms (3). Here the cobaltous atoms are obviously ionic whereas the cobaltic atoms are assamed to be held mainly by covalent bonds by analogy with other cobaltic complexes 
for which magnetic susceptibility data are available.

Another experiment illustrating good correlation between covaleney and no exchange and between ionic binding and rapid exchange was carried out by F.A.Long in 1941. (11). The research reported on the exchange between free oxalate ions and complex oxalates of fron and cobalt. From measurements of ma gnetic susceptibility it appears that the bonds between the central atom and the oxalate ions in the cobalt complex are covalent whereas in the iron complex they are mainly electrovalent. When these complexes are brought Into aqueous solution as the alka li salts in the presence of free oxalate ions labelled with $c^{\prime \prime}$ it is found that ferric trioxalate exchanges rapidly whereas the cobalt complex shows no exchange.

S. Ruben states that, "many examples may be cited to support the notion that electrovalent linkages lend themselves to rapid exchange and covalent linkages do not. However the cogeny of examples such as those cited is weakened by the fact that in practically all cases the exchange is observed in a polar solvent in which dissociation equilIbria operate and what is usually being measured is merely the tendency of lonic linkages to ionize. It is not difficult to find systems in which the readiness of atoms to exchange bears little relation to the assigned bond type". (20)

There is no exchange between magnesium ions and the magnesium porphyrin, chlorophyll, dissolved in an $80 \%^{\wedge}$ solution. One may assume the central magnesium atom to be held 
primarily by electrovalent linkage because of the high degree of electropositive character of magnesium compared to the coordinating nitrogen atoms of the pyrrole constituents of chlorphyll. Nor does exchange occur between $\mathrm{Fe}^{+++}$ and ferriheme, ferrihemoglobin, ferric pheophytin and ferric tetraphenylporphin, or between $\mathrm{Cu}^{++}$and cupric pheophytin using various mixed sovents to effect a homogeneous system (20). In ferriheme or ferrihemoglobin, and presumably in the other porphins cited, the magnetic data indicate mainly electrovalent bonding. Yet no exchange occurs.

Another interesting experiment was carried out using the compound ferrous $\alpha, \alpha^{\prime}$-dipyridyl sulfate $\left(\mathrm{C}_{10} \mathrm{H}_{8} \mathrm{~N}_{2}\right)_{3}-$ $\mathrm{FeSO}_{4} \cdot$ The complex salt is known to be diamagnetic and Pauling has concluded that the Fe-N bonds are therefore mainly covalent. Nevertheless an exchange of about $25 \%$ with $\mathrm{Fe}^{+t}$ in aqueous solution was noted after two hours (20). From a consideration of the data available at present it appears that there need be no systematic correlation between covalency or electrovalency and rate of isotopic exchange. The factors which influence such exchange, 1.e. strength of bond, steric hindrance, solvent interactions, equivalent states available, etc., are not yet clearly defined or separable for either extreme type of bonding, let alone for mixed types. Therefore it is permissible only to make the rather attenuated statement that any atom bound in a molecule whether by a covalent or electrovalent bond, will not exchange with similiar atoms in another molecular species unless a mechanism exists for bringing such atoms 
reversibly into equivalent states.

It is becoming more apparent to investigators in

these researches, that structural relations are very important and perhaps predominate over bond type in determining exchange rate. In the porphin type structures already mentioned it is necessary to break a "fused" ring, i.e. four bonds must be broken simultaneousiy. Hence one may expect little or no exchange because the "fused" ring structure does not permit the escape of the central atom and the equilibrium involved is practically irreversible in favor of the bound atom. In exchangeable compounds with a ring consisting of separated molecules instead of a "fused" ring type, trere exists the possibility of stepwise dissociation with equilIbria involving molecular species in which the metal ion is held by two or less bonds.

It has seemed of interest to extend these investigations to another "bound atom" type structure, namely, graphite ferric chloride $\left(\mathrm{C}_{12} \mathrm{FeCl}_{3}\right)_{\mathrm{n}}$. X-ray studies have shown that the $\mathrm{Fe}^{+++}$ions between the large layer-planes of tightly bonded carbon atoms of the graphite lattice, form a triangular planar network above and below which there is a parallel net plane of $\mathrm{Cl}^{-}$ions. Rlldorff (22) has found that the magnetic moment of the $\mathrm{Fe}^{+++}$ions in the compound is unchanged with that of $\mathrm{Fe}^{+++}$ions in $\mathrm{FeCl}_{3}$ and suggests that the bonding of the ferric chloride in the lattice is the result of a polarization of the conductivity electrons of the carbon layer-planes toward the central iron ions. 
This explanation seoms valid, for it would be difficult to account for the extreme inactivity exhibited by graphite ferric chloride if one was to assume that the metallic chloride was held by no more than the van der Waals forces betweon the lattice layer-planes.

From a consideration of the configuration of atoms around the $\mathrm{Fe}^{+++}$ions in this "sandwich" structure for $\left(C_{12} \mathrm{FeCl}_{3}\right)_{n}$, it seemed unlikely that the iron ions in the compound would exhibit any rapid exchange with $\mathrm{Fe}^{+++}$ions In a queous solution. The series of experiments to be described herein was done to determine whether such exchange took pla ce under any of a variety of conditions. 
B. The Szllard-Chalmers Reaction in the Chain Reacting Pile.

A well known field of nuclear chemistry based on the special properties of recoil atoms is that of the szilardChalmers reaction, wherein the radioactive atoms from neutron activation separate themselves from the bulk of material being irradiated (36) (30). The radiative capture of a neutron by a stable nucleus is an important nuclear reaction, which frequently gives rise to a useful radioisotope. However, the chemical identity of the active isotope with the unchanged target element places serious limitations on the specific activities obtained by this reaction. The szilard-Chalmers reaction, which effects separation of the activated atoms from the target material by virtue of the gamma-ray recoil, can be used to enhance the specific activity of the active material under favorable circumstances.

Three conditions have to be fulfilled to make a Szilard-Chalmers chemical separation possible,(1) The radioactive atom in the process of its formation must be broken loose from its molecule and it must not recombine with the molecular fragment from which it separated. (2) The element must be capable of existence in at least two mutually stable and separable forms. (3) At least two of these forms must show lack of rapld isotopic exchange.

Most chemical bond energies are in the range of 1 to $5 \mathrm{ev} \cdot(20-100 \mathrm{k}$. cal. per mole). In any nuclear reaction involving heavy particles either entering or leaving the nucleus with energies in excess of 10 or $100 \mathrm{kev}$. the kinetic 
energy imparted to the residual nucleus far exceeds the magnitude of bond energies. In the case of thermal-neutron capture, where the szilard-Chalmers method has its most important applications, the incident neutron does not impart nearly enough energy to the nucleus to cause any bond rupture. But neutron capture by a nucleus is accompanied by the release of 8 or $9 \mathrm{m.e.v}$. of evergy in the form of several energetic gamma quanta. The recol.l energy thus imparted to the capturing atom may be as much as one hundred times as great as the energies of the chemical bonds in which it participates. Thus in most $n, \gamma$ processes the probability of bond rupture is very high.

The third condition for the operation of the szjlardChalmers method requires at least that thermal exchange be slow between the radioactive atoms in their new chemical state and the inactive atoms in the target compound. However, the energetic recoil atoms may undergo exchange more readily than atoms with ordinary thermal energies. It is these exchange reactions and other reactions of the high-onergy recoil atoms ("hot atoms") that determine to ai large extent the separation efficiencios obtainable in szilard-Chalmers processes (36). Recent attempts to enrich activities produced in the high flux of the chain-reacting pile have shown the high gamma and neutron radiation fields cause marked chemical changes in the bombarded"compounds aside from the effects of accompanying activation. That such reactions may yield products similiar to those obtained in activation reactions is to be expected, since both types are essentially a decomp- 
osition by excitation. But radiation decomposition can Jield small amounts of the chemical form in which the activity is found, thus diluting the active isotope. It is also possible that the radiation field will cause further chemical reactions of the separable active isotope which may change it: to a form which is no longer separable, or cause some of the initially separated activity to be lost by a radiation-induced back reaction. As suggested by $R \cdot R$. Willlams, the rate of decomposition is undoubtedly related to different flux components from those responsible for activation (36). Variations among these components must be elininated or measured before a quantitative test of the proposed rate equations will be possible. Many workers are engaged in a study of these processes and it is likely that much more than the present qualitative data will soon be available.

The reactions which the "hot" atom or fragment will undergo depend to some extent on the nature of its environment and in this connection the present research on the effect of pile irradiation on graphite ferric chloride $\left(\mathrm{C}_{12} \mathrm{FeCl}_{3}\right)$ was carried out.

The largest amount of work in the field of SzilardChalmers sepa rations has been done on halogen compounds (29) (32). Many different organic halides (including $\mathrm{C}_{2} \mathrm{H}_{5} \mathrm{I}, \mathrm{CH}_{3} \mathrm{I}$, $\mathrm{CCl}_{4}, \mathrm{C}_{2} \mathrm{H}_{4} \mathrm{Cl}_{2}, \mathrm{C}_{2} \mathrm{H}_{5} \mathrm{Br}, \mathrm{C}_{2} \mathrm{H}_{2} \mathrm{Br}_{2}, \mathrm{C}_{6} \mathrm{H}_{5} \mathrm{Br}$ ) have been irradiated and the products of neutron capture reactions $\left(I^{128}, C_{1}^{38}\right.$, $\mathrm{Br}^{80}$, $\mathrm{Br}^{82}$ ) removed by various techniques. Seiparations of ha logens with 70 to 100 per cent yields have also been 
obtalned in neutron irradiations of solid or dissolved chlorates, bromates, lodates, perchlorates and periodates.

The bombardment of metal-organic compounds and complex salts is often useful for szilard-Chalmers separatlons if the free metal ion does not exchange with the compound and if the two are separable. Some of the compounds which have been used successfully are: cacodylic acid $\left(\mathrm{CH}_{3}\right)_{2} \mathrm{AsOOH}$, from which As ${ }^{76}$ can be separated as silver arsenite in $95 \%$ Jleld; copper salicylaldehyde o-phenylene diamine, from which as much as $97 \%$ of the $\mathrm{cu}^{64}$ activity can be removed as $\mathrm{Cu}^{++}$ ion; uranyl benzoylacetonate. $\mathrm{JO}_{2}\left(\mathrm{C}_{6} \mathrm{H}_{5} \mathrm{COCHCOCH}_{3}\right)_{2}$, from which $\mathrm{U}^{239}$ activity has been extracted in about $10 \%$ yield. It has been suggested that metal ion complexes which exist in opt1cally active forms and do not racemize rapidiy may be generally suitable for szilard-Chalmers processes because the metal Ion in such a complex is not expected to exchange rapidy with free metal ion in solution. Some complexes of this type have been used successfully, e.g. the triethylenediamine nitrates of iridium, platinum, rhodium, and cobalt.

Recent studies of the irradiation of these cobalt complexes have shown the dependence of a successful. Szilard-Chalmers' reaction on the configuration of the complexing molecules surrounding the central metallic atom. P. Stle and $G$. Kayas in 1948, irradiated in a neutron flux, the threo cobalticomplexes, hexamine cobalt III nitrate $\mathrm{Co}\left(\mathrm{NH}_{3}\right)_{6}\left(\mathrm{NO}_{3}\right)_{3}$, triethylenediamine cobalt III nitrate $\mathrm{Co}(\mathrm{en})_{3} \quad\left(\mathrm{NO}_{3}\right)_{3}$ and diethylenetriamine cobalt III nitrate 
Co(tri) $2\left(\mathrm{NO}_{3}\right)_{3}$ (3i). They found for all three compounds, that isotopic exchange, within experimental errors, was nil. The percent jields of separated activity, however, varied greatly for the three compounds. From salt no. I, hexamine cobalt III nitrate, they were able to extract $86 \%$ of the total activity as the hydroxide. From salt no.II, where the ethylenediamine molecules each take up two positions in the octahodral configuration of the cation, the amount of the activity separated dropped to $75 \%$ of the total In the case of salt no.III, diethylenotriamine cobalt III nitrate, the ethylenetrlamine molecules each cover three positions of the octahedral arrangement around the central cobalt atom. Here the szilard-Chalmers separation was successful to the extent of only $10 \%$.

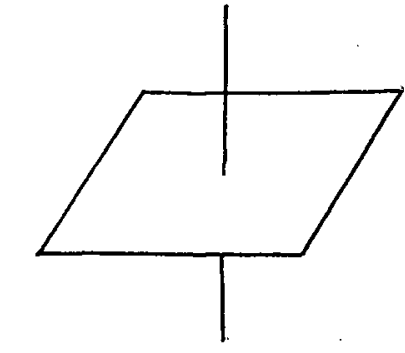

$\mathrm{Co}\left(\mathrm{NH}_{3}\right)_{6}\left(\mathrm{NO}_{3}\right)_{3}$

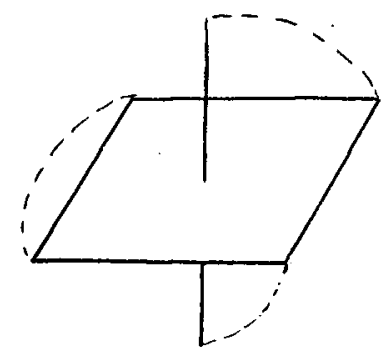

$\mathrm{Co}(\mathrm{en})_{3}\left(\mathrm{NO}_{3}\right)_{3}$

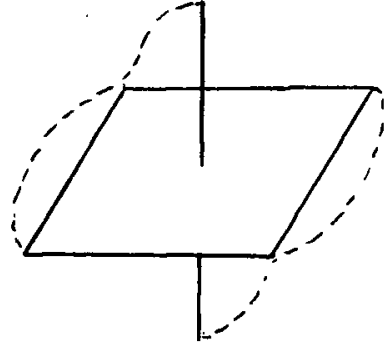

$\operatorname{coltri})_{2}^{\left(\mathrm{NO}_{3}\right)_{3}}$

Figure 5 - Steric hindrance in cobalt.complexes.

These somewhat conclusive results are explained by the authors who state that when an activated recoiling atom of this type is surrounded by a number of large interfering molecules, 
that it is more or less improbable that there will follow any bond rupture allowing the ejection of the "hot" atom from the compound. It is assumed that, under the effect of the shock, the coordinating chain enters into vibration and absorbs sufficient energy to prevent the recoll atom from leaving the molecule. This steric effect results in the production of an active compound with most of the $\mathrm{A}^{+1}$ isotople atoms still bonded in the same position as the neutron capturing atom they replaced.

It is suggested that, in the case of a coplanar molecule, this steric effect would not be as pronounced, leading to a fairly high jield of separated activity. It may be of interest to mention that szilard-chalmers reaction on uranium by means of uranylsicylaldehyde o-phenylenedilmine gives a Field of about $80 \%(14)$. The central atom of this compound is enclosed in a large and coherent organic molecule and the high yield is likely due to the probable coplanarity of the molecule which enables the uranium atom to escape.

Consider now the case of the very stable graphite ferric chloride $\left(\mathrm{C}_{12} \mathrm{FeCl}_{3}\right)_{\mathrm{n}}$ with the ferric chloride molecules bound between the layer-planes of carbon atoms in the graphite lattice. As has been suggested, the probability of any rapid 1sotopic exchange between ferric ions in solution and the iron existing as ferric chloride bound in the graphite lattice, seems somewhat remote. It is therefore likely that any iron activity separated by a Szilard-Chalmers process on this compound could be obtained in high specific activity. 
However the configuration of atoms surrounding each iron atom in this "sandwich" structure, would very definitely be expected to contribute to a large retention of the activity by recombination reactions, and result in a low jield of separated activity following neutron irradiation.

The success of a Szilard-Chalmers separation on $\left(\mathrm{C}_{12} \mathrm{FeCl}_{3}\right)_{\mathrm{n}}$ was determined following irradiation of a dry purified sample of the compound in Canada's National Research Council atomic pile. The results and discussion of these experiments follow in the experimental section of this paper. 


\section{RADIOCHEMICAI TECHNIQUES.}

In radioactive tracer exporiments, a radioactive 1sotope is used as an indicator to trace or follow the path taken by the inactive isotope. The radioactive isotope decays with the emission of alpha, beta, or gamma rays, or possibly positrons and these radiations can be measured with a suitable instrument such as an ionization chamber or a Geiger counter. By taking sultable precautions, the measurements can be made quantitative.

The decay of a radioactive substance follows the exponential law

$$
N=N_{0} e^{-\lambda t}
$$

where $\mathbb{N}$ is the number of unchanged atoms at time $t$, $\mathbb{N}$ is the number present at $t=0$, and $\lambda$ is the decay constant. The

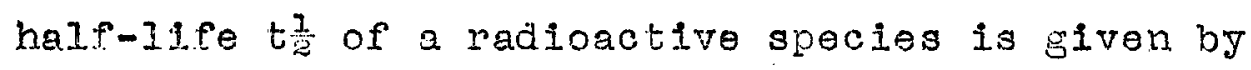

$$
t_{\frac{1}{2}}=\frac{\ln 2}{\lambda}
$$

In practical work the number of atoms $n$ is not directiy evaluated, a nd even the rate of changedv/dt is usually not measured absolutely. The usual procedure is to determine the activity $A$, with $A=C \lambda N$. The detection coefficient $\mathrm{C}$, depends upon the nature and efficiency of the recording instrument and the geometrical arrangement of sample and detector. In cases where the decay of the radioactive spectes is appreciable during the course of the experiment it is necessary to correct for the resulting decrease in actIvity before comparative determinations can be obtained. The limit of sensitivity of a Gelger-Mulier counter Is set by the baclsground counting rate which must be subtrac- 
ted to find the activity of the sample. By sheathing the enclosed counter with a few centimeters thickness of lead most of the ionization from small amounts of activity present as impurities in construction materials, and from the appreciable and variable amount of radon, thoron, and their decay products contained: in the air, can be eliminated. However the cosmic-rag effect will still be significant and results in a background counting rate of from 20-25 counts per minvite.

Because radioactive decay is a random process, ultimate accuracy in assay of radioactivity is limited by statistical fluctuations inherent in counting data. This random phenomenon is subject to established methods of statistical analysis which have been verified abundantly by experiment. The term "standard deviation" as used in the experimental section of this thesis is equal to the square root of the number of counts observed. The probable error, defined as the error which is as likely to be exceeded as not, is 0.6745 times the standard deviation. In general, the counting is suffLient in duration to make the standard deviation less than errors from non-statistical sources such as sampling uncertalnties and uncontrollable chemical losses.

In the research to be described, only relative counts from activities were required and many of the corrections necessary to obtain an absolute count, such as external absorption loss, backscattering and sample geometry, were eliminated by standardization of counting techniques. A complete description of the experimental methods followed in 
this research has been included in the experimental section of the thesis. It has seemed more convenient to leave any discussion concerning the validity of counting rate results and the justification of the manner of handing the required correction problems until that more appropriate time. 
1. Preparation of Graphite Ferric Chloride, $\left[\mathrm{C}_{12}{ }^{F \theta C I_{3}}\right] \mathrm{n}$. In view of the nature of the experiments to be carrled out, it was declded that the fully intercalated graphite ferric chloride $\left[\mathrm{C}_{12} \mathrm{FeCl}_{3}\right] \mathrm{n}$ would be better suited to our purpose than the second compound containing less ferric chloride. Accordingly, it was the compound containing about 56\% ferric chloride which was prepared in all cases by keeping the reaction temperature below $309^{\circ} \mathrm{C}$.

a.) Anhydrous Ferric Chloride: Dry $\mathrm{Cl}_{2}$ was passed over C.P. Iron powder contalned in an electrically heated Pyrex tube at $350^{\circ} \mathrm{C}$. Beautiful hexagonal platelets of a deop red wine color formed throughout the cool portion of the tube. Dry air was admitted during the cooling and the crystals were removed and handled only in a dry box. To prepare the active chloride, radioactive iron wire was used together with the powder.

b.) $\mathrm{C}_{12} \mathrm{FeCl}_{3}$ : Acid purified, 200 mesh graphite, (G-66 Graphite powder-Fisherscientific Co.) was mixed with three times its welght of anhydrous ferric chloride, sealed in a Carius bomb tube, and heated for twelve hours at $305^{\circ} \mathrm{C}$. The approximately $47 \%$ of the reaction product which is excess ferric chloride was removed by successive refluxings with hot $6 \mathrm{~N}$ HCl. After a total washing time of 36 hours a further refluxing at. $100^{\circ} \mathrm{C}$ with a one gram sample gave no test for $\mathrm{Fe}^{+++}$with $\mathrm{NH}_{4 \mathrm{r}} \mathrm{CNS}$ or less than $4.3 \mu \mathrm{gm}$. Fe as determined radiometricaliy. $6 \mathrm{~N} \mathrm{NaOH}$ at $80^{\circ} \mathrm{C}$ showed no action on the 
graphite ferric chloride after purification. The compound was stable in air and decomposed at temperatures only above $309^{\circ} \mathrm{C}$ (with evolution of $\mathrm{FeCl}_{3}$ vapour).

From the initial weight of craphite and final weight of compound, the percentage composition was determined and found always to correspond to $\mathrm{C}_{12} \mathrm{FeCl}_{3}$, a compound containing 53\% ferric chlorlde. According to Rlldorff (22) this same composition results throughout the preparation range 200 to $309^{\circ} \mathrm{C}$. and independently of the original graphite crystal form (8).

$\mathrm{X}$-ray diffraction measurements on the $\mathrm{C}_{12} \mathrm{FeCl}_{3}$ powder, made with a Phillips-Geiger Counter X-ray Spectrometer and using the $1.539 \AA$ cu line, showed three peaks at $d=9.40$, 4.66 and $3.13 \AA$. The first of these has been interpreted by Rlldorff as the separation of the planes of carbon atoms. His value was $9.4 \AA$.

In the three tables which follow, are set down the numerical results from $x$-ray diffraction measurements on graphite, anhydrous ferric chloride and $\mathrm{C}_{12} \mathrm{FeCl}_{3}$. In the colurn headed "degreas" is listed the blaroing angle, equal to twice the $\theta$ in the $3 r a g s$ equation $n \lambda=2 d \sin \theta$. The second columa contains the values of $d$, the distances between reflecting atomic planes. The values $I / I_{0}$ listed in the third column, are the ratios of the intensity of the reflected beam of $x$-rays to the greatest intensity observed. The values listed for anhydrous ferric chloride in Table II. have been obtained from the literature. Tables I and III contain the 
values obtained for graphite and $\mathrm{C}_{12} \mathrm{FeCl}_{3}$ from diffraction measurements made in the laboratories of the British Columbia Research Council, who so kindly permitted the use of their $\mathrm{X}$-ray spectrometer. 


\section{TABLE I}

X-ray Diffraction Measurements on Graphite

Graphite 3.36

$1.68 \quad 2.02$

\begin{tabular}{|c|c|c|}
\hline Degrees $(2 \theta)$ & $\mathrm{d} \AA$ & $I / I_{0}$ \\
\hline 24.0 & 3.701 & 0.13 \\
\hline 26.5 & $3 \cdot 36$ & 1.0 \\
\hline 41.2 & 2.187 & 0.1 \\
\hline $42 \cdot 2$ & 2.137 & 0.13 \\
\hline 43.0 & 2.100 & 0.16 \\
\hline $44 \cdot 8$ & 2.02 & 0.3 \\
\hline 46.0 & 1.969 & 0.12 \\
\hline 50.2 & 1.82 & 0.1 \\
\hline 54.5 & 1.68 & 0.7 \\
\hline 56.2 & 1.63 & 0.09 \\
\hline 60.0 & 1.539 & 0.1 \\
\hline 61.6 & 1.503 & 0.06 \\
\hline 77.0 & 1.236 & 0.21 \\
\hline 83.7 & 1.154 & 0.19 \\
\hline 85.0 & 1.139 & 0.06 \\
\hline 86.4 & 1.122 & 0.13 \\
\hline
\end{tabular}




\section{TABLE II}

X-ray Diffraction Measurements on Anhydrous Ferric Chloride. $x$

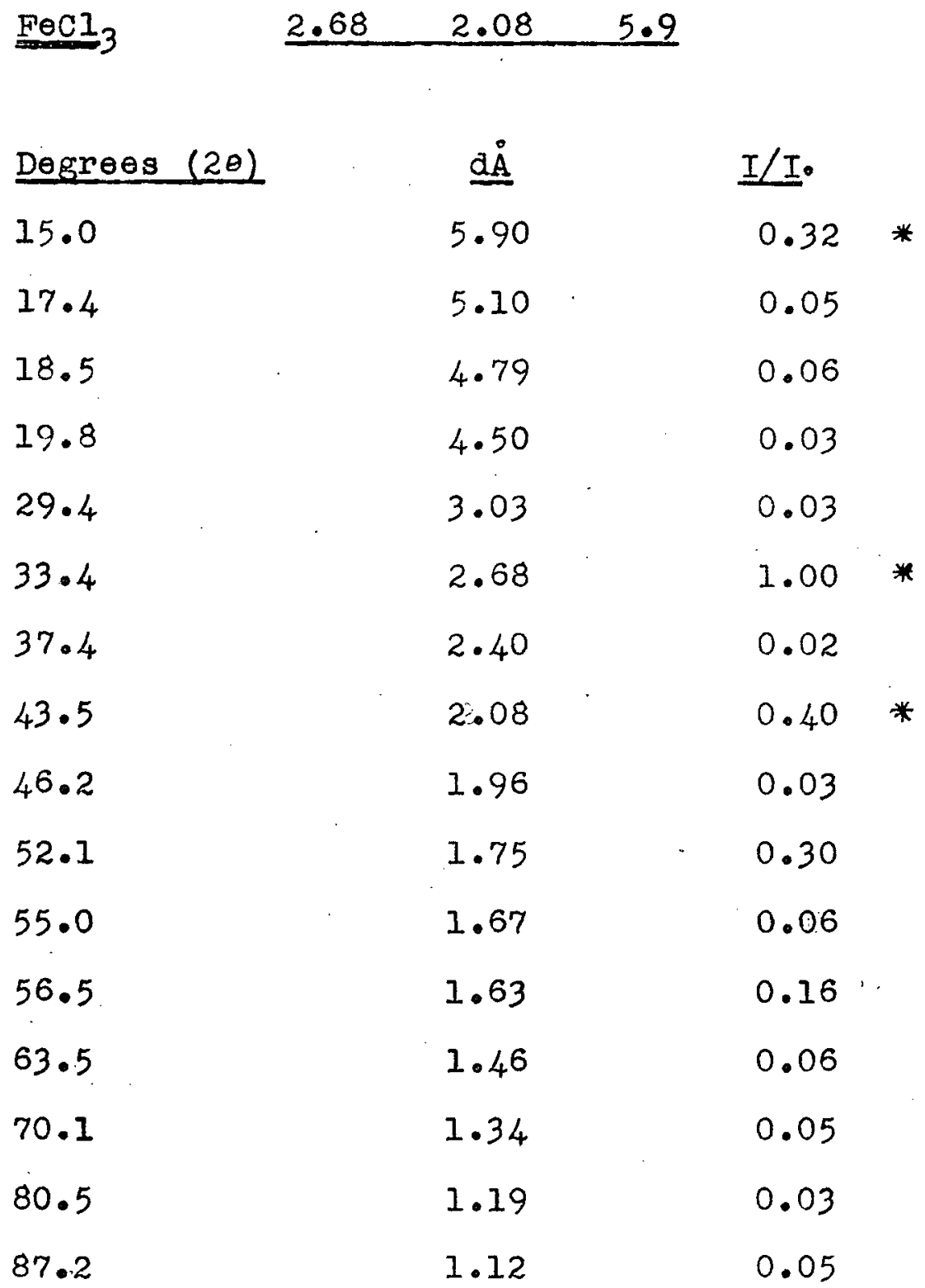

$x$ A.S.T.M.Philadelphia,Fa., X-ray diffraction powder patterns J.D.Hanawalt and co-workers, card index. 


\section{TABLE III}

X-ray Diffraction Measurements on Graphite

Feric Chloride $\mathrm{C}_{12} \mathrm{FeCl}_{3}$.

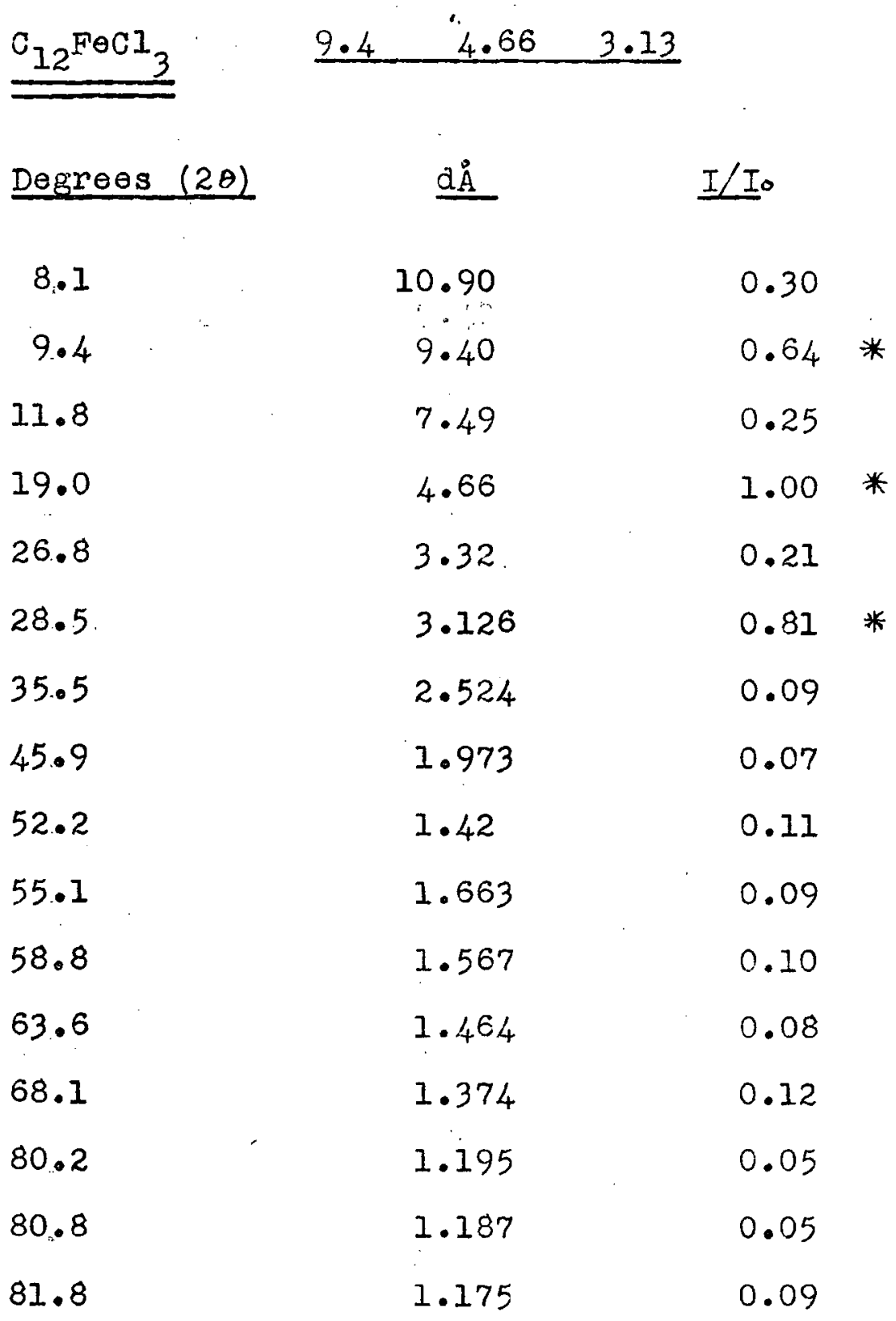




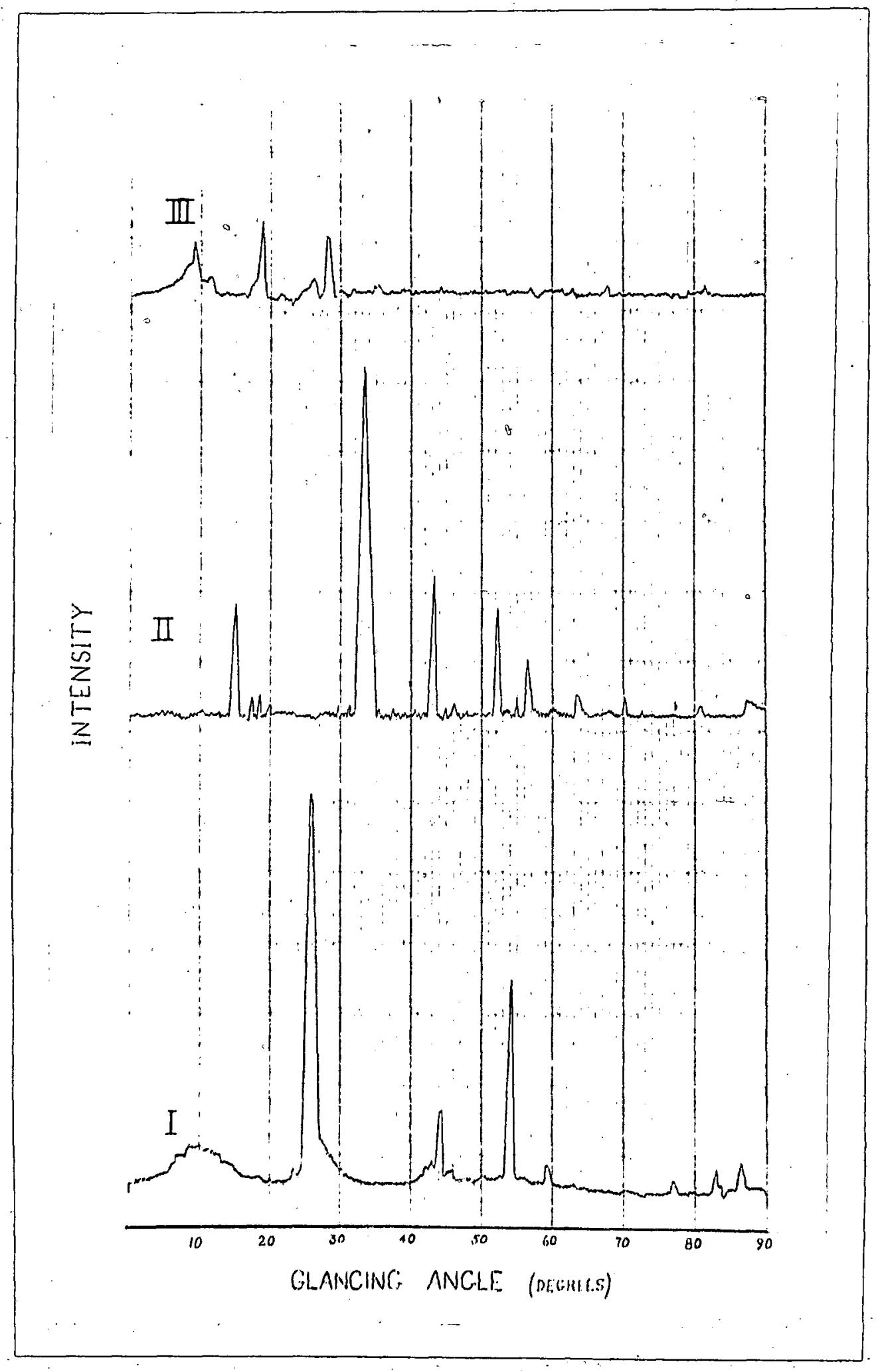

$$
\begin{aligned}
& \text { Plate I : X-Ray diffraction patterns of } \\
& \text { I - Graphite } \\
& \text { II - Anhydrous Ferric Chloride } \\
& \text { III - Graphite Ferric Chloride. }
\end{aligned}
$$


Plate I shows the comparison between the three X-rayi" diffraction diagrams. I - graphite, II - anhydrous ferric chloride and III - graphite ferric chloride $\left(\mathrm{C}_{12} \mathrm{FeCl}_{3}\right)$. It will be seen that the pattern for graphite ferric chloride is distinctly different from that of either graphite or ferric chloride a nd it is apparent that no free ferric chloride exists in the compound.

The value obtained for the percentage ferric chloride in the compound compares very well with the limiting value of $\mathrm{FeCl}_{3}: \mathrm{C}$ equal to $1: 12.04$ required by the crystal structure as determined by Rlldorff. Rigorously purified specimens gave the consistent figure 53\% ferric chloride, which corresponds to a $\mathrm{FeCl}_{3}: \mathrm{C}$ ratio of $1: 12.02$. This figure which is somewhat better than the value $1: 11.9$ reported by Rldorff (22) is probably due to the longer period of acid-leach purification employed in this work.

In view of the experiments to follow, it was necessary to determine to what degree of certainty the last traces of free ferric chloride had been removed from the purified $\mathrm{C}_{12} \mathrm{FeCl}_{3}$

1). 5 gms. of $\mathrm{C}_{12} \mathrm{FeCl}_{3}$ were purified by successive refluxings in $6 \pi$. HCl for thirty-six hours. This specimen was then treated to a further refluxing in $100 \mathrm{mls}$. of $6 \mathrm{~N}$. $\mathrm{HCl}$ for six hours, and the acid extract tested for $\mathrm{Fe}^{+++}$ with $1 \% \mathrm{NH}_{4} \mathrm{CNS}$ solution. The $\mathrm{NH}_{4} \mathrm{CNS}$ reaction with $\mathrm{Fe}{ }^{+++}$ which is vell adapted to spot tests has a sensitivity of $0.25 \mu \cdot g \cdot m$. Fe ${ }^{+++}$and a concentration limit of 1 in 200,000 . 
The acid extract solution was evaporated to $10 \mathrm{mls}$. before testing. $1 \mathrm{ml}$. portions gave no coloration with the reagent and were therefore assumed to contain less than $5 \mu \mathrm{gm}$. $\mathrm{Fe}^{+++}$. Therefore the $100 \mathrm{ml}$. acid extract from the $5 \mathrm{gm}$. sample of $\mathrm{C}_{12}{ }^{\mathrm{FeCl}} 3$ could not have contained more than $50 \mu \cdot \mathrm{gm} . \mathrm{Fe}^{+++}$, or less than $10 \mu . \mathrm{gm} . \mathrm{Fe}^{+++}$per gram of graphite ferric chloride tested.

2). A second test for completeness of removal of free $\mathrm{Fe}^{+++}$was made using radioactive $\mathrm{C}_{12} \mathrm{FeCl}_{3}$. The active $\mathrm{C}_{12} \mathrm{Fe}^{*} \mathrm{Cl}_{3}$ was measured at $229 \times 10^{3}$ counts per minute per gm. which was equivalent to $229 \times 10^{3}$ c.p.m. from 0.1820 gm. Fe - The sample was treated by the 36 hour washing procedure and then examined as follows:

5 gms. $\mathrm{C}_{12} \mathrm{Fe}^{*} \mathrm{Cl}_{3}$ refluxed with $100 \mathrm{mls}$. $6 \mathrm{~N}$ HCl for 4 hours.

The $100 \mathrm{ml}$. acid solution was evaporated to $10 \mathrm{ml}$. and tested for activity.

Iml. acid extract soln. gave $440 \pm 21$ counts/10 min. $=44 \pm 2 c \cdot p \cdot m$.

Background count $=44 \pm 2 \mathrm{c} \cdot \mathrm{p} \cdot \mathrm{m}$.

$$
\text { Probable error } 0.6745 \times 2= \pm 1.35 \mathrm{c} . \mathrm{p} \cdot \mathrm{m} \text {. }
$$
Maximum activity due to $\mathrm{Fe}^{+++}$in extract $=2 \times 1.35$ c.p.m./ml. $=2.7 \times 10 \mathrm{c} \cdot \mathrm{p} \cdot \mathrm{m}$. in total volume of extract. $229 \times 10^{3}$ c.p.m. are recorded from $0.1820 \mathrm{gm}$. Fe.

$\therefore$ Max, Fe in acid extract $\frac{27}{229 \times 10} 3 \times 0.1820=21.5 \mu \cdot \mathrm{gm}$. from

$$
5 \mathrm{gm} \cdot\left(\mathrm{C}_{12} \mathrm{FeCl}_{3}\right)
$$

$\therefore$ less than $4.3 \mu . g m$. Fe extractable/gm. $\mathrm{C}_{12} \mathrm{FeCl}_{3}$ 
From a consideration of the above results it appeared reasonably certain that we were dealing with $\mathrm{C}_{12} \mathrm{FeCl}_{3}$, and of sufficient purity to be suitable for use in the following experiments on exchange and the szilard-chalmers reaction. 
2. Tests for Exchange between Graphite Ferric Chloride $\mathrm{C}_{12} \mathrm{FeCl}_{3}$ and Ferric 1on, using Radioactive $\mathrm{Fe}^{59}$.

The exchange experiments were performed by shaking: portions of finely powdered radio-active graphite iron (59) III chloride in solutions of inactive ferric lon of various P.H.'s, temperatures, and solvents. The reverse procedure, using radioactive iron (59) JII chloride solutions, was also carried out in some cases. These mixtures were mechanically shaken for various lengths of time, then separated by centrifuging. Aliquots were withdrawn and the specific activity of the active components determined from the counting rate, corrected for decay.

The conditions of the experiments were varied considerably but the same general procedure was followed in every case. Tests for exchange were carried out in acid media. As well as ferric chloride, aqueous solutions of ferric nitrate and ferric sulfate were mixed with the active compound. To test the effect of temperature on the rate of exchange all the mixtures in aqueous media were shaken at temperatures of both 20 and $80^{\circ} \mathrm{C}$. The influence of solvent interaction on the exchange was observed by carrying out experiments using ferric chloride dissolved in ethanol, diethyl ether, iso-propyl ether, acetone and benzyl alcohol. In one experiment using benzyl alcohol as the media, tests for exchange betweon graphite ferric chloride and ferric lons were made at a temperature of $190^{\circ} \mathrm{C}$. 
Radioactivity Measurements: Pure iron wire was activated in the neutron flux of the Canadian N.R.C. pile at Chalk River, ontario. A mixture of the 47 day $F e^{59}$ emitting 0.26 and $0.46 \mathrm{Mev}$. beta's and 1.10 and $1.30 \mathrm{Mev}$. gamma's and the: 4 year $\mathrm{Fe}^{55}$ which decays by $\mathrm{K}$ capture emitting 0.07 Mev $\mathrm{X}-$ rays, was received with an activity of $0.059 \mathrm{mc} . \mathrm{Fe}^{59} / \mathrm{gm}$. plus about $0.29 \mathrm{mc} . \mathrm{Fe} / \mathrm{gm}$. This was mixed with Fe powder and converted to ferric chloride as already described. The decay curve (Fig. VI), over a five month period is linear with a $\mathrm{T} \frac{1}{2}$ of 47 days, indicating no need for a correction for the weak $\mathrm{Fe}{ }^{55}$ radiation.

Measurements were made with an "end on" G.M. self quenching counter made by the U.B.C. Physics De:partment. It had a $3 \mathrm{mg} . / \mathrm{cm}^{2}$ window $2.0 \mathrm{~cm}$. In diameter, and a 150 volt plateau which was flat within $1 \%$ statistical error and over which the count increased $8 \%$. (Fig. VII) The counter was mounted on a lucite base and shielded to a background count of $42 \pm 2$ counts per minute. The pulses were counted by a Nuclear Instrument Co. Nodel 163 scaling unit. Response was Iinear to $2 \%$ up to 3300 counts/minute.

Samples were counted on $I^{\prime \prime}$ diameter watch glasses, placed in an easily reproducible position about $3 \mathrm{~cm}$. below the counter window. The samples of graphite ferric chloride compared were always less than $0.2 \mathrm{mg}$. per $\mathrm{cm} .^{2}$ and hence no self absorption correction was made in calculating specific activity. The initial activity was $0.1 \mu \mathrm{c}$. per gm. of compound, corrected only for background. The evaporated ferric chloride solution samples however, were often thick 


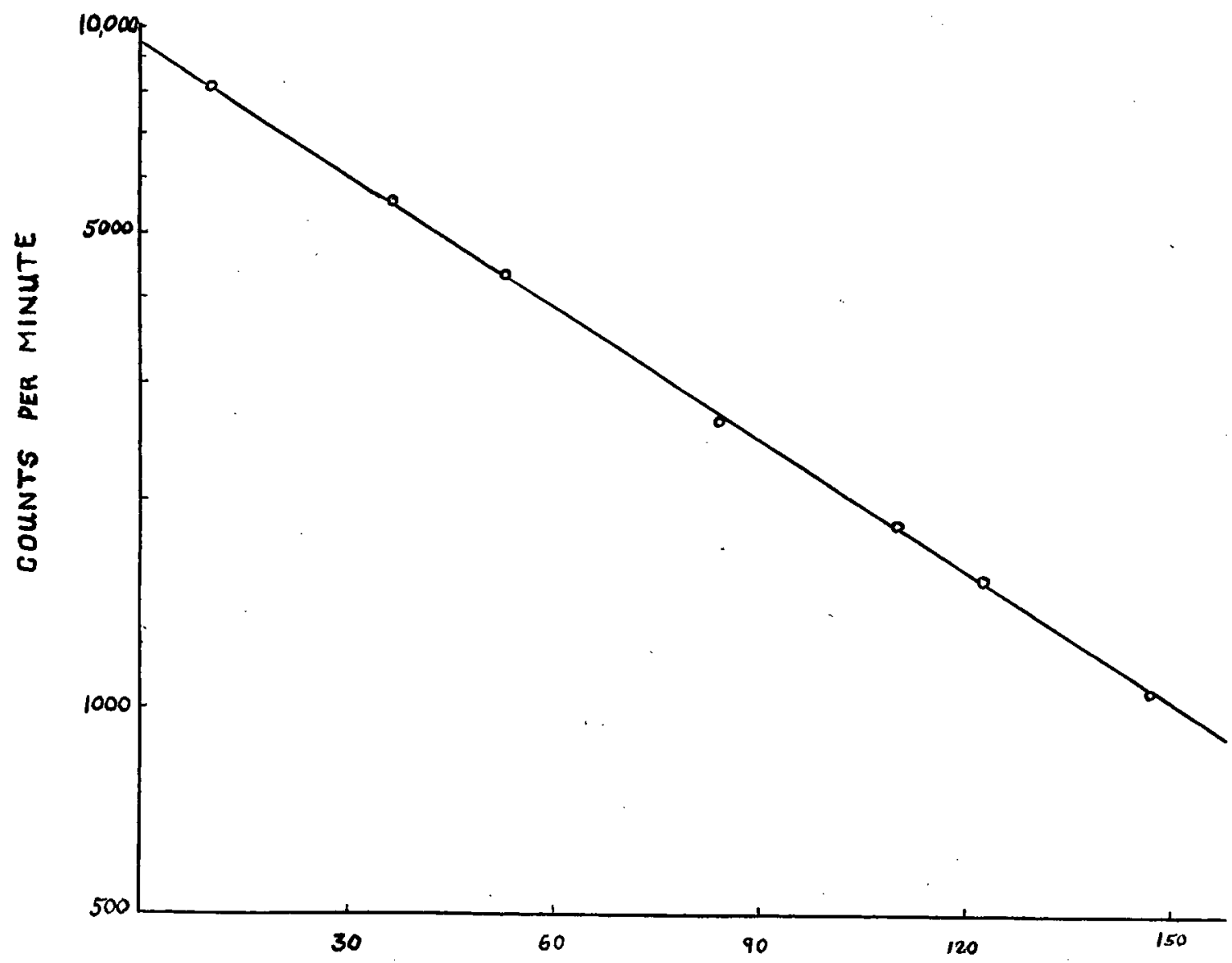

TIME IN DAYS

Figure VI - Rate of decay of radioactive $\mathrm{Fe}^{59}$. 


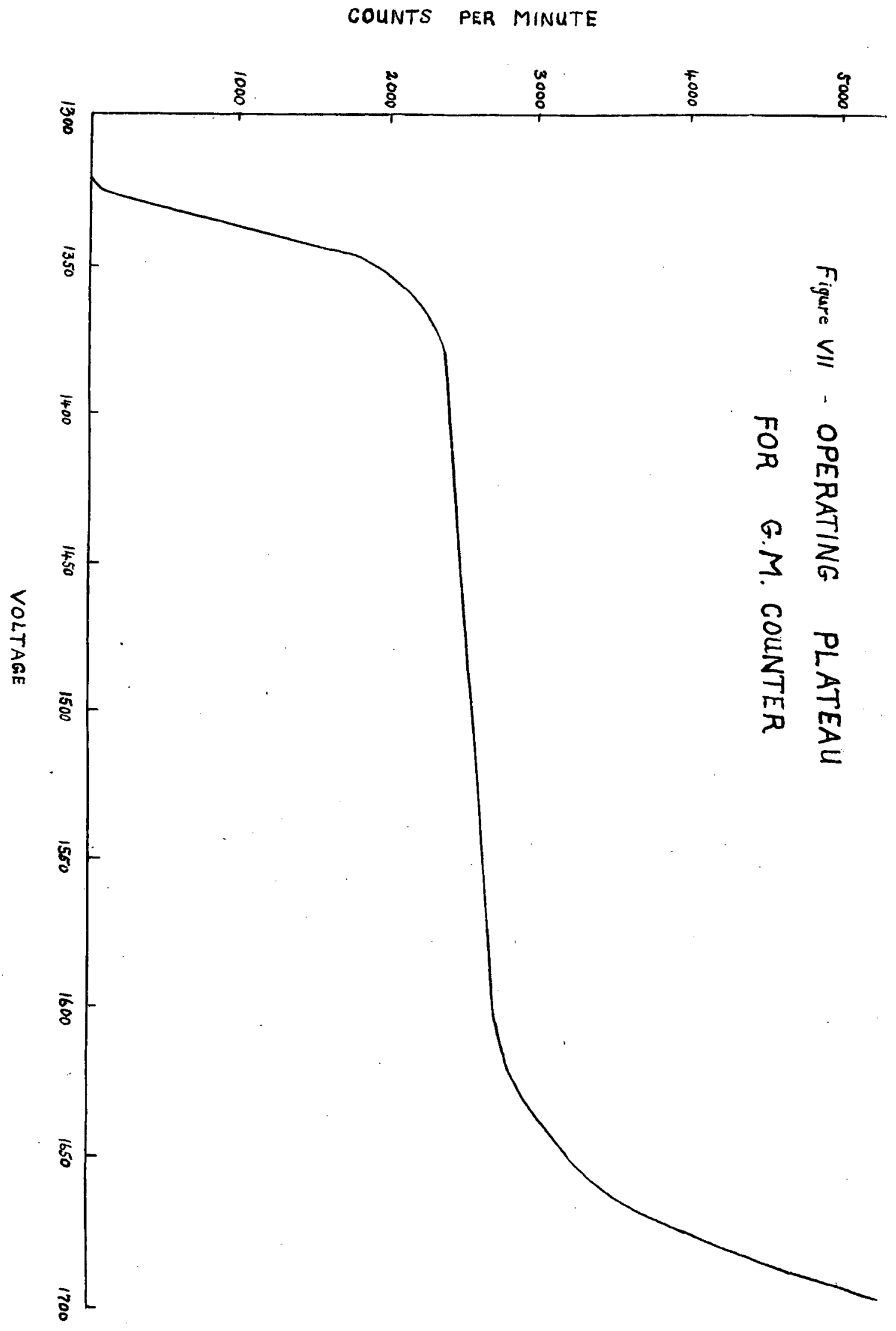


enough to require a self absorption correction. This was handled in the usual fashion. Aliquots of $0.2,0.4,0.6$ and $0.8 \mathrm{ml}$. of solution were pipetted onto the watch glasses, evaporated to dryness using an infra red lamp, and counted. The measured activity per unit volume of sample in each case was calculated (apparent specific activity), and plotted agalnst the actual volume of the sample used. From this curve, extrapolated to zero volume (1.e. zero thickness of sample) was obtained the true specific activity. The solutions of radioactive iron (59) III chloride used were prepared from a standard $0.4 \mathrm{~N}$ solution of $\mathrm{P} . \mathrm{H} .1 .0$. The activity of this solution corrected as above and for background was 580 counts per minute per $\mathrm{mg}$. of iron. Later measurements of both solid and solution were corrected for decay back to this time.

Exchange Measurements: A 0.01 to $0.15 \mathrm{gm}$. sample of $\mathrm{C}_{12} \mathrm{FeCl}_{3}$ was mechanically shaken with $5 \mathrm{ml}$. of a solution containing ferric ion and centrifuged. The specific activity of the washed solid and of the solution were determined ( and corrected for background and decay, and in the case of the evaporated solution aliquot, for self absorption) as described above.

The variations made in the conditions were:

1) P.H. : 0.2 to 3.0

2.) Temperature : 20 to $80^{\circ} \mathrm{C}$. for water and to $190^{\circ}$ for benzyl alcohol.

3) Solvent for $\mathrm{FeCl}_{3}$ : water, ethanol, acetone, diethyl ether, isopropyl ether, benzyl alcohol. 
4) Anion : chloride, nitrate, sulfate.

5) Active iron in the compound only or in the solution only.

6) Time of shaking.

7) Concentration of ferric ion and weight of compound. 
RESULTS AND DISCUSSION.

The data obtained on the exchange of graphite ferric chloride and ferric ions in acid solution, are presented in Table I. The quantity I/c represents the specific activity expressed in arbitrary units. I is the counting rate in counts per minute corrected for decay, and $C$ is the number of mililgrams of iron present in the sample of the graphite ferric chloride being counted. In column 7 is recorded the specific activity of the original graphite iron (59) III chloride, in column 8 its specific activity after remaining for the recorded length of time in the solution described, and in the last column the specific activity calculated for complete exchange.

The results of the experiments reported in Table I show that no appreciable exchange takes place between $\mathrm{C}_{12} \mathrm{Fe}^{*}-$ $\mathrm{Cl}_{3}$ and $\mathrm{Fe}^{+++}$in acid solution within periods of time up to twelve hours. Further observations on some of these reaction mixtures were made after they had been shaken for ninetysix hours, and again after standing in the laboratory for a period of four months. In all cases the exchange was negligible. (Table II).

Reaction temperatures above room temperature were obtained by connecting a hot water circulatory system to the mechanical shaker. Where tests for exchange were made using an aqueous medium a maximum temperature of $80^{\circ}$ was used. Table III shows the results obtained from comparisons at different temperatures, of tests for exchange 
Tests for Exchange between $\mathrm{C}_{12} \mathrm{Fe}^{*} \mathrm{Cl}_{3}$ and $\mathrm{Fe}^{+++}$in Aqueous Acid Solut1on at $20 \pm 2^{\circ} \mathrm{C}$.

\begin{tabular}{|c|c|c|c|c|c|c|c|c|c|c|c|}
\hline No. & $\begin{array}{c}\mathrm{C}_{12} \mathrm{Fe}^{*} \mathrm{Cl}_{3} \\
\text { gms. }\end{array}$ & $\begin{array}{l}\mathrm{FeCl}_{3} \\
\text { soln. }\end{array}$ & mis. & $\begin{array}{l}\text { Conc. of } \\
\mathrm{FeCl}_{3} \mathrm{M}\end{array}$ & P.H. & $\begin{array}{l}\text { Time of } \\
\text { Shaking }\end{array}$ & $\begin{array}{c}\text { I/C } \\
\text { (original) }\end{array}$ & $($ obs. at time $t)$ & 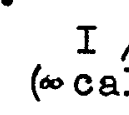 & $\begin{array}{l}1 c \\
I c .)\end{array}$ & \\
\hline 1. & 0.025 & 5 & & 0.01 & 1.1 & 4 min. & $1259 \pm 9$ & $1257_{ \pm} 8$ & 780 & & \\
\hline 2 & 0.025 & 5 & & 0.01 & 1.1 & $2 \mathrm{hrs}$ & $1259 \pm 9$ & $1251+10$ & 780 & & \\
\hline 3 & 0.010 & 5 & & 0.05 & 3.0 & I hr. & $1260 \pm 10$ & $1249 \pm 14$ & 145 & & \\
\hline $4 \cdot$ & 0.010 & 5 & & 0.05 & 3.0 & $8 \mathrm{hrs}$ & $1260+10$ & $1249 \pm 12$ & 145 & & \\
\hline 5. & 0.025 & 5 & & 0.10 & 1.2 & 4 min. & $1260 \pm 10$ & $1253+14$ & 176 & & \\
\hline 6. & 0.025 & 5 & & 0.10 & 1.2 & $2 \mathrm{hrs}$ & $1260 \pm 10$ & $1262 \pm 10$ & 176 & $\cdot 1$ & \\
\hline 7 . & 0.030 & 5 & & 0.167 & 1.0 & 4 min. & $1257_{ \pm} 11$ & $1254 \pm 10$ & 131 & 背 & \\
\hline 8 & 0.030 & 5 & & 0.167 & 1.0 & $6 \mathrm{hrs}$ & $1257_{ \pm} 11$ & $1251 \pm 11$ & 131 & $\cdot I_{H}$ & \\
\hline 9. & 0.025 & 5 & . & 0.25 & 1.0 & 4 min. & $1255 \pm 8$ & $1261 \pm 10$ & 78 & & \\
\hline 10 & 0.025 & 5 & & 0.25 & 1.0 & $12 \mathrm{hrs}$ & $1255 \pm 8$ & $1260 \pm 9$ & 78 & & \\
\hline 11. & 0.025 & 5 & & $0: 10$ & $2 \cdot 5$ & $8 \mathrm{hrs}$ & $1257 \pm 11$ & $1259 \pm 10$ & 176 & & \\
\hline 12 & 0.050 & 5 & & 0.5 & 0.5 & $1 \mathrm{hr}$. & $1250 \pm 10$ & $1254 \pm 10$ & 78 & & \\
\hline 13. & 0.050 & 5 & & 0.5 & 0.5 & $4 \mathrm{hrs}$ & $1250 \pm 10$ & $1246 \pm 10$ & 78 & & \\
\hline 14. & 0.100 & 5 & & 0.78 & 0.2 & $4 \min$ & $1258 \pm 8$ & $1252 \pm 10$ & 100 & & \\
\hline 15. & 0.100 & 5 & & 0.78 & 0.2 & $4 \mathrm{hr}$ & $1258 \pm 8$ & $1254 \pm 10$ & 100 & & \\
\hline 16. & 0.100 & 5 & & 0.78 & 0.2 & $10 \mathrm{hrs}$ & $1258 \pm 8$ & $1246 \pm 12$ & 100 & & \\
\hline 17. & 0.150 & 5 & & 1.0 & 0.5 & 4 min. & $1252 \pm 10$ & $1260 \pm 10$ & 123 & & \\
\hline 18. & 0.150 & 5 & & 1.0 & 0.5 & $8 \mathrm{hrs}$ & $1252 \pm 10$ & $1248 \pm 10$ & 123 & & \\
\hline
\end{tabular}


To. $I / C \quad I / C \quad I / C \quad: I / C \quad I / C$

No. Composition P.H. (original) (after 4min. (after 96hrs. (after 4mo. (ocalc.) shaking) shaking) contact)

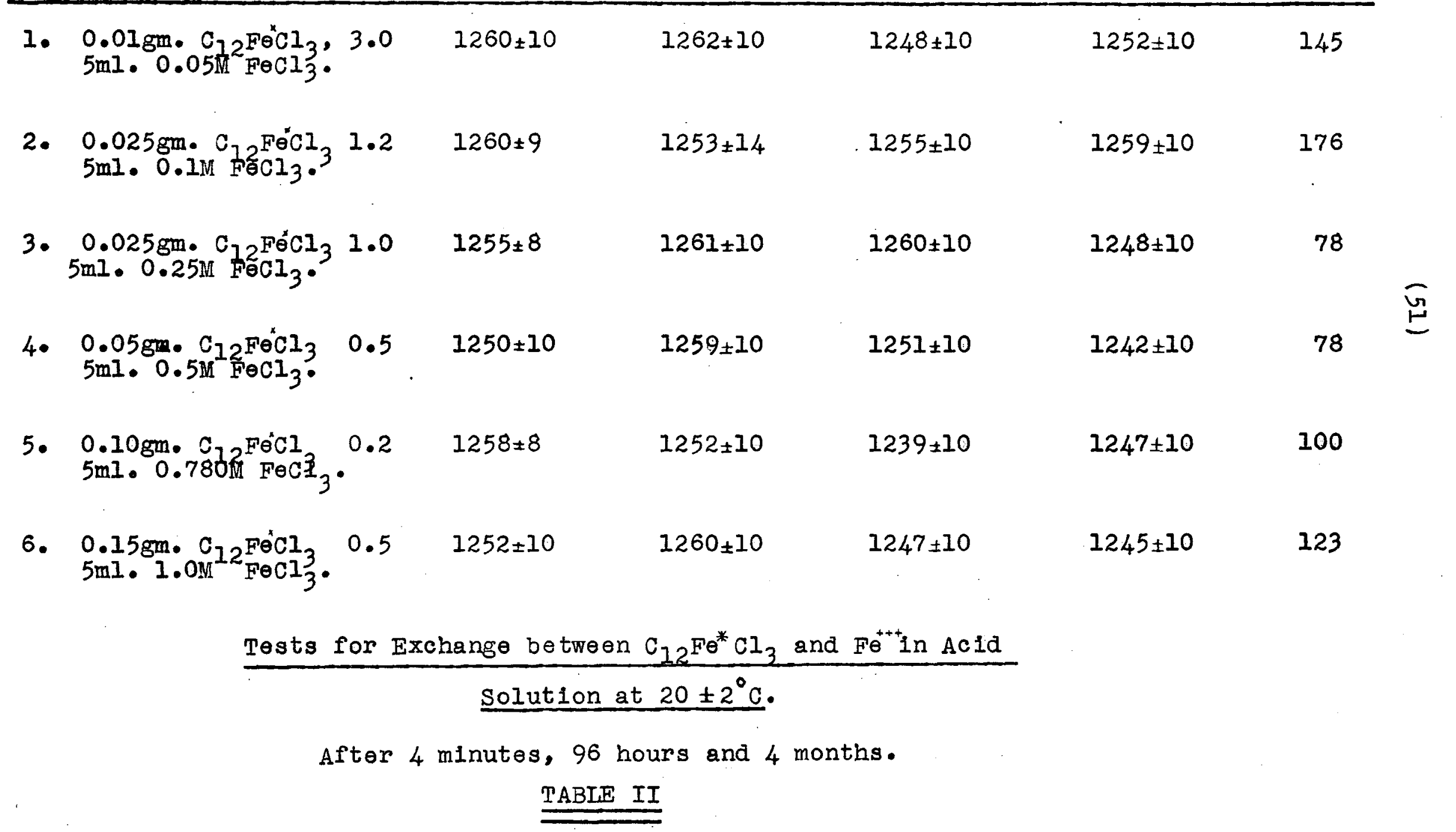




\section{TABLE III}

Effect of Temperature on Tests for Exchange between

$\mathrm{C}_{12} \mathrm{FeCl}_{3}^{*}$ and $\mathrm{Fe}^{+++}$in Varlous Acld Solutions.

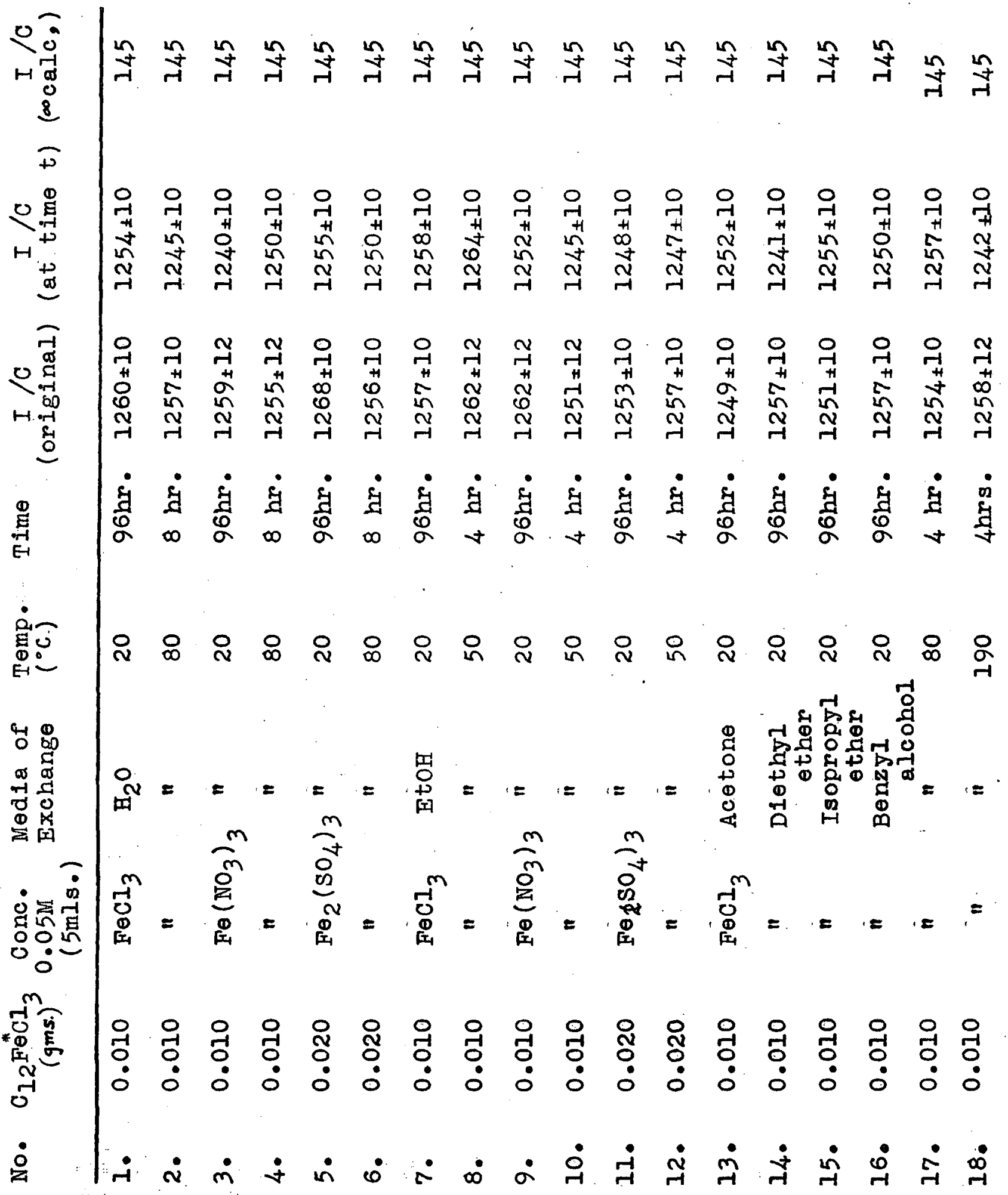


between graphite ferric chloride and ferric iron in solutions of water, ethyl alcohol, acetone, diethyl ether, isopropyl ether and benzyl alcohol: The influence of both solvent interaction and temperature appear to be nil. Even atatemperature of about $190^{\circ} \mathrm{C}$ with boiling benzyl alcohol no exchange was observed after four hours refluxing.

To complete the rather strong evidence that no exchange takes place between $\mathrm{C}_{12} \mathrm{FeCl}_{3}$ and $\mathrm{Fe}^{+++}$, one further set of experiments was performed. In the experiments set forth in tables I, II and IIT, radioactive graphite iron (59) III chloride was brought into contact with inactive ferric iron in solution and after suitable periods of time the components were separated and their speciflc activity ascertained. In no instance was any appreciable activity detected in the inactive iron containing species nor was there any transfer of activity from the solid compound.

In the above experiments however, no account was taken of the possibility of preferential adsorption of the migrating active ions by the active compound. If exchanging active 1ons, trapped in the complex by capillary condensatIon were not removed by washing the compound before counting, there would of corarse be no decrease in the specific activity of the solid. Likewise no increase in the activity of the ferric ion solution would be observed. Therefore tests for exchange between radioactive iron (59) III chloride and inactive graphite ferric chloride were carried out. The results of these experiments are shown in table IV. 


\begin{tabular}{|c|c|c|c|c|c|c|c|c|}
\hline No. & $\begin{array}{l}\mathrm{Fe}^{*} \mathrm{Cl}_{3} \\
5 \mathrm{mls} \\
(\mathrm{Mo})\end{array}$ & $\mathrm{PH}$ & $\underset{\left(\text { gms }^{\mathrm{m}}\right)}{\mathrm{C}_{12} \mathrm{FeCl}_{3}}$ & $\begin{array}{c}I / c \\
\text { (original) }\end{array}$ & $\begin{array}{c}I / c \\
(\operatorname{after} 4 \mathrm{hrs} .)\end{array}$ & $\begin{array}{c}I / C \\
\text { (after } 96 \mathrm{hrs} .)\end{array}$ & $\begin{array}{c}I / c \\
\text { (after } 4 \mathrm{mo} .)\end{array}$ & $\begin{array}{c}I / c \\
\text { (o calc. }\end{array}$ \\
\hline 1. & 0.4 & 1.0 & 0.150 & $582 \pm 6$ & $584 \pm 6$ & $580 \pm 6$ & $570 \pm 6$ & 468 \\
\hline 2. & 0.25 & 1.0 & 0.150 & $580 \pm 5$ & $581 \pm 5$ & $584 \pm 5$ & $578 \pm 5$ & 417 \\
\hline 3. & 0.10 & 1.0 & 0.150 & $581 \pm 6$ & $580 \pm 6$ & $587 \pm 6$ & $585 \pm 6$ & 292 \\
\hline 4. & 0.08 & 1.0 & 0.150 & $584 \pm 6$ & $575 \pm 6$ & $578 \pm 6$ & $570+6$ & 262 \\
\hline 5. & 0.06 & 1.0 & 0.150 & $582 \pm 6$ & $580 \pm 6$ & $582 \pm 6$ & $576 \pm 6$ & 220 \\
\hline 6. & 0.04 & 1.0 & 0.150 & $580 \pm 6$ & $572 \pm 5$ & $572 \pm 5$ & $569 \pm 6$ & 170 \\
\hline 7. & 0.01 & 1.0 & 0.150 & $579 \pm 6$ & $575 \pm 6$ & $579 \pm 6$ & $574 \pm 6$ & 54 \\
\hline 8. & 0.005 & 1.0 & 0.150 & $580 \pm 6$ & $581 \pm 6$ & $580 \pm 6$ & $578 \pm 6$ & 28 \\
\hline
\end{tabular}

Tests for Exchange Between $\mathrm{FE}^{*++}$ and $\mathrm{C}_{12} \mathrm{FeCl}_{3}$ in Aqueous ACid

Solution at $20 \pm 2^{\circ} \mathrm{C}$.

TABLE IV. 
As before, no measureable exchange was observed even after long perlods of time. The samples of inactive graphite ferric chloride were easily washed clear of any activity following separation from the radioactive ferric chloride solution. 


\section{The Szilard Chalmers Reaction with Graphite Ferric Chloride.}

It has been shown that there is no measurable exchange between $\mathrm{C}_{12} \mathrm{Fe} \mathrm{Cl}_{3}$ and ferric ion in surrounding solution. It is therefore likely that any iron activity separated by a szilard-chalmers process on the compound could be obtalned in high specific activity. It is of intorest to note the success of a szilard-Chalmers separation, with regard to the structure of this compound.

Pure $\mathrm{C}_{12} \mathrm{FeCl}_{3}$ was irradiated in the neutron flux of the Canadian N.R.C. pile at Chalk River; ontario. The activity of the compound was measured, the separated portion of activity removed in hot hydrochloric acid solution, and the yield calculated.

1.50gms. of $\mathrm{C}_{12} \mathrm{Fe} \mathrm{Cl}_{3}$ powder (containing $0.27 \mathrm{gm}$. Fe) were activated by 48 hours irradiation at about 3.9 $10^{12} \mathrm{n} \cdot / \mathrm{cm}^{2} / \mathrm{sec}$. A mixture of the 47 day $\mathrm{Fe}{ }^{59}$ and 4 year $\mathrm{Fe}^{55}$ was obtained, but as well, the reactions occuring on neutron irradiation of chlorine resulted in the production of four other active isotopes. $\mathrm{cl}^{35}$ undergoes an $(n, \gamma)$ reaction to produce the $10^{6}$ year $\mathrm{Cl}^{36}$ emitting $0.66 \mathrm{MeV}$. bota's, an $(n, p)$ reaction producing 87 day $s^{35}$ which emits 0.17 Mev. beta's, and also an $(n, x)$ reaction to 14.7 . day $\mathrm{p}^{32}$ emitting 1.7 Mev. beta's. $\mathrm{Cl}^{37}$ also undergoes an $(\mathrm{n}, \gamma)$ reaction to $\mathrm{Cl}{ }^{38}$ which has a 37 minute half 1 lfe and decays with the emission of $1.1,238$ and 5.0 Mev beta's and 1.65 and $2.15 \mathrm{Mev}$. gamma's. 
Because of its long half life, the $\mathrm{Cl}^{36}$ radioactivity developed is negligible when relatively short irradiation periods are used. Short-lived $\mathrm{Cl}^{38}$ decays in a day or so. Contamination by $\mathrm{P}^{32}$ is of the order of $1 \%$ of the total $\mathrm{s}^{35}$, in terms of beta particles emitted (35). The initial activity of the irradiated compound was estimated at 0.008 mc. $\mathrm{Fe}^{59} / \mathrm{gm}$. $0.027 \mathrm{mc} \cdot \mathrm{F}^{55} / \mathrm{gm}$. and $1.27 \mathrm{mc} \cdot \mathrm{s}^{35} / \mathrm{gm}$. The separated portion of the activity from the szilard-chalmers reaction would then be expected to be composed mainly of these three radioactive isotopes. The iron activitiescan be separated by a very efficient and simple $\mathrm{s}^{35}$ extraction procedure based on the solvent extraction of ferric chloride (34). In the experiments reported here, diethyl ether was used as solvent. The partition coefficient for extraction of ferric chloride by diethyl ether from aqueous $6 \mathrm{~N}$ hydrchloric acid is about 100 .

$0.100 \mathrm{gm}$. of pile irradiated graphite ferric chloride was refluxed with constant boiling $(\sim 6 \mathrm{~N})$ hydrochloric acid for six hours and the aqueous solution separated by centrifuging. A few drops of $30 \%$ hydrogen peroxide were added, to ensure that all the iron was present as ferric ion. The colorloss aqueous solution was shaken with successive $1 / 4$ volumes of diethyl ether saturated with hydrochloric acid, and finally washed with an equall volume of solvent. The ether extracts were then collectively stripped with distilled water. The radioactivity of the resultant solutions was measured and the components differentiated by adsorption meas- 
urements. .

Figures VIII, IX and $\mathrm{X}$ give the absorption curves for the aqueous, residue solution, the stripped ether, and the water extract respectively. It is evident that no detectable amount of radioactive iron remains' in the aqueous residue, nor can the activity of $\mathrm{S}^{35}$ be detected in the extract. Apparently the $\mathrm{P}^{32}$ is present in a form which has a small but measurable partition coefficient, as it is extractable to some extent. The small amount of $s^{35}$ taken up by the solvent (possibly as sulfur chloride) is not re-extracted by distilled water. The chemical form of the $s^{35}$ in the aqueous residue is presumably as $\mathrm{Fe}_{2}\left(\mathrm{~S}^{35} \mathrm{O}_{4}\right)_{3}$. In a similiar type of solivent extraction of irradiated $\mathrm{FeCl}_{3}$, M.B. Wil (35) has reported $99.5 \%$ of the original $\mathrm{s}^{35}$ and $83 \%$ of the $\mathrm{p}^{32}$ to be contained in the aqueous residue solution which is free of detectable $\mathrm{Fe}^{59}$. The stripped ether portion contained only the remaining $0.5 \%$ of the $\mathrm{s}^{35}$ and $0.01 \%$ of the $\mathrm{P}^{32}$. All the original $\mathrm{Fe}^{59}$ and the small amount of remaining $P^{32}$ was found in the water extract which was free of detectable $\mathrm{s}^{35}$ activity.

The total activity of the hydrochloric acid solution, which had been refluxed for six hours with the $0.100 \mathrm{gm}$. sample of irradiated $\mathrm{C}_{12} \mathrm{FeCl}_{3}$, was measured at $0.682 \%$ of the activity of the untreated compound. No detectable activity was obtained in a further treatment with hot HCl solution.

The very low energy of the beta particles from $\mathrm{s}^{35}$ 


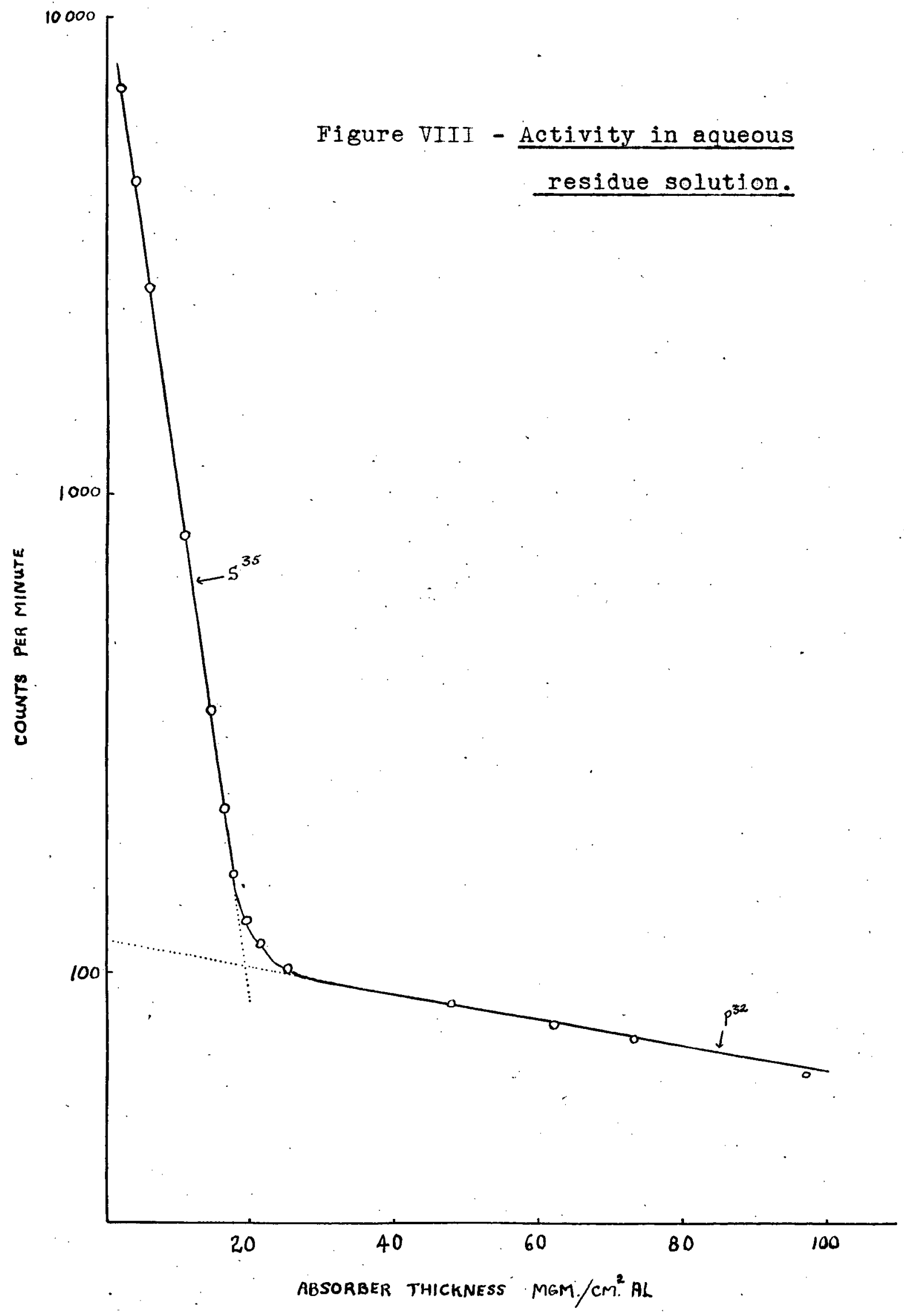




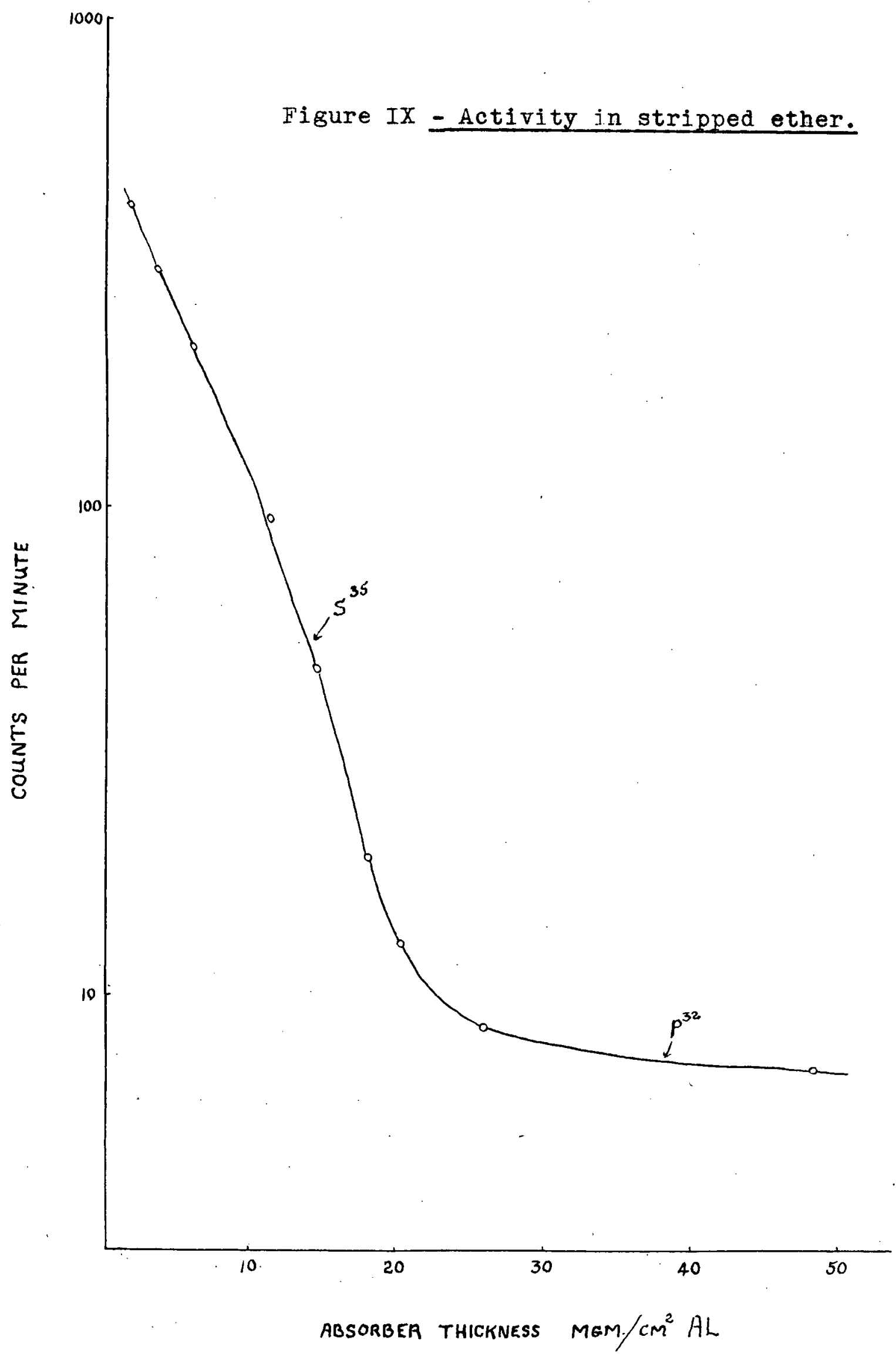




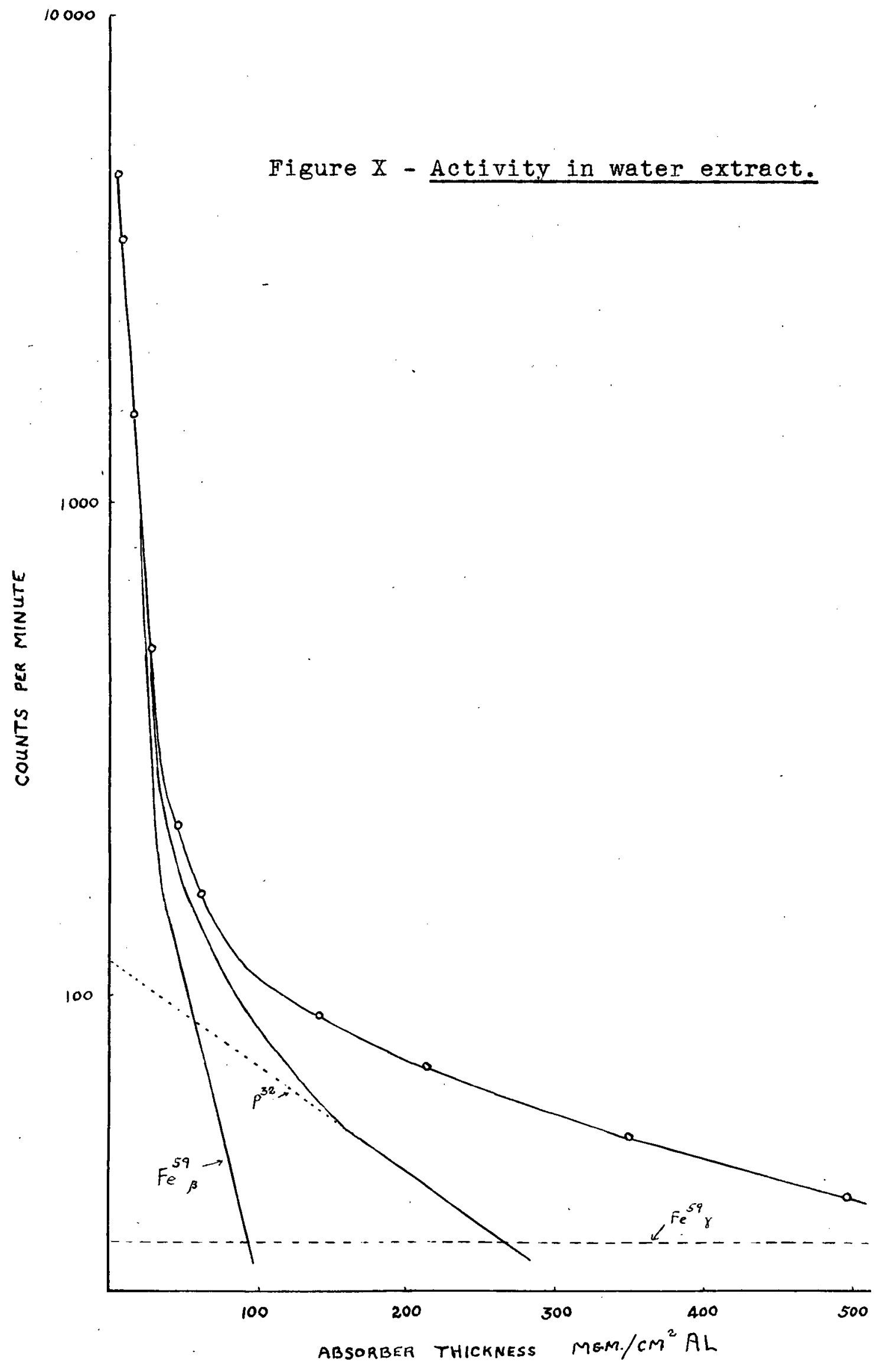


poses special problems as regards their quantitative detection. The low energy of the radiation makes the self-weakening effect a major one. Experiments have shown that samples of thickness $3 \mathrm{mgm} . / \mathrm{cm}^{2}$ will be weakened to the extent of $40 \%$ of the total activity (35). In activity measurements of the various solutions involved, the self absorption corrections were obtained in the same manner as already discussed under exchange experiments. The graphite ferric chloride samples compared were always less than $0.2 \mathrm{mgm} / \mathrm{cm}^{2}$. The activity of the irradiated $\mathrm{C}_{12} \mathrm{FeCl}_{3}$ was compared with the activity of hydrochloric acid solution containing the separated isotopes, by absorption measurements on the two. Both samples measured were less than $0.2 \mathrm{mgm} . / \mathrm{cm}^{2}$. Figure XI gives the absorption curves comparing I - irradiated $\mathrm{C}_{12} \mathrm{FeCl}_{3}$ and II - evaporated acid extract solution. It will be seen that the two absorption curves are identical. From this it seems apparent that the component radioactive isotopes exist in the activity separated by the Szilard Chalmers reaction in the same ratio as they are present in the irradiated compound. A third series of absorption measurments on the irradiated compound from which the separated portion of activity had been removed gave a curve identical with the other two.

It is apparent that some of the recoiling atoms of both chlorine and iron have achieved bond mupture and ejection from the $\mathrm{C}_{12} \mathrm{FeCl}_{3}$ lattice. However, the very low fraction of the total activity separated in hot hydrochloric 


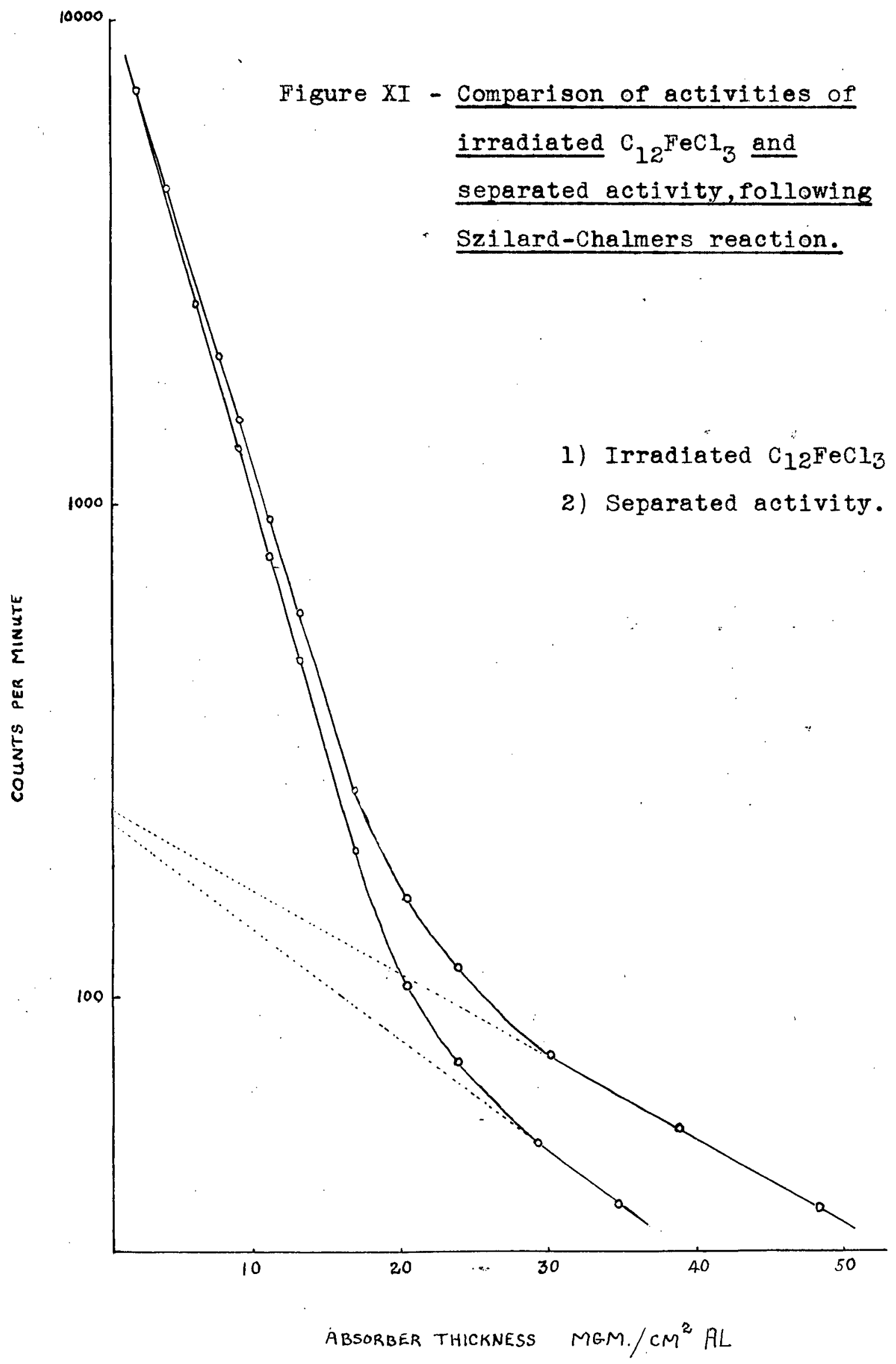


acid, indicates that almost all the neutron capturing atoms are still firmly bound in the graphite compound. A series of experiments, designed to see whether or not changing the method of recovering the separated activity would result in a larger szilard-Chalmers yleld, was carried out. Samples of the irradiated compound that were refluxed with $\sim 6 \mathrm{~N}$ HCl for four, eight and sixteen hours, relinquished no more of their total activity than did a sample which was washed for 15 minutes in a solution of $4 \mathrm{~N} \mathrm{HCl}$ at $80^{\circ} \mathrm{C}$. The valuesfor the percentage of total activity separated, which were obtained from these experiments, were all within the range 0.681 to $0.688 \%$. It was noted, however, that if the irradlated graphite ferric chloride was subjected to a fine grinding previous to the acid-leach treatment, the fraction of actlvity separated increased slightly. The percentage yiteld was raised from about $0.684 \%$ to an average value of $0.727 \%$ by grinding the samples by hand in a mortar or between ground-glass plates. The use of a fine aluminum oxide grinding powder raised this value to $0.737 \%$. The results from these above experiments are listed in Table V.

In all cases the aqueous acid solutions containing the separated activity, were colorless and gave no test for $\mathrm{Fe}^{\text {t+t }}$ with $\mathrm{NH}_{4} \mathrm{CNS}$. It is therefore apparent that little or no radiation decomposition takes place as a result of the irradiation of the compound. It is unfortunate that the small amount of iron separated is not detectable by other than radiochemical methods, as facilities for handing the large 


\section{TABLE V.}

The Effect of Different Extraction Methods on

\section{the \% Szilard Chalmers Separation.}

Exp. Conditions for acid

No. extraction of separable activity from $\mathrm{C}_{12} \mathrm{FeCl}_{3}$.
Initial separated activity activity in of $\mathrm{C}_{12} \mathrm{FeCl}_{3} \mathrm{HCl}$ soln. $\left(c \cdot p \cdot m_{\bullet}\right) \quad\left(c \cdot p \cdot m_{0}\right)$ \%szilard Chalmers separation.

1. $0.0827 \mathrm{gm}$. in $4 \mathrm{~N} \mathrm{HCl}$

$58.11 \times 10^{5} \quad 39.6 \times 10^{3}$

0.681

at $80^{\circ} \mathrm{C}$. Stirred in

blender for $15 \mathrm{~min}$.

2. $0.200 \mathrm{gm}$. in $\sim 6 \mathrm{NHCl}$ at

$134.32 \times 10^{5} 92.4 \times 10^{3}$

0.688

$100^{\circ} \mathrm{C} \cdot$ Refluxed for 4 hours.

3. $0.200 \mathrm{gm}$. in $\sim 6 \mathrm{~N} \mathrm{HCI}$

$120 \times 10 ?^{5} \quad 82 \times 10^{3}$

0.683

at $100^{\circ} \mathrm{C}$. Refiuxed for 8 hours.

4.0 $0.1523 \mathrm{gm}$. in $\sim 6 \mathrm{~N} \mathrm{HCI}$

$87.06 \times 10^{5} 59.4 \times 10^{3}$

0.682

at $100^{\circ} \mathrm{C}$. Refluxed for 16 hours.

5. $0.1094 \mathrm{gm}$. in $\sim 6 \mathrm{~N} \mathrm{HCI} \quad 38.56 \times 10^{5} \quad 28.08 \times 10^{3} \quad 0.728$ at $25^{\circ} \mathrm{C}$ : Ground in

a mortar (approx. I hr.)

6. $0.0482 \mathrm{gm}$. in $\sim 6 \mathrm{~N} \mathrm{HCl} 11.99 \times 10^{5} \quad 8.7 \times 10^{3} \quad 0.7255$

at $100^{\circ} \mathrm{C}$. Sample ground

between two ground-glass

plates before acid.

extraction.

7. $\quad 0.0530 \mathrm{gm} \cdot$ in $\sim 6 \mathrm{~N} \mathrm{HCl} \quad 13.187 \times 10^{5} 9.72 \times 10^{3} \quad 0.737$ at $100^{\circ} \mathrm{C}$. Sample ground as in \#6, but with fine $\mathrm{Al}_{2} \mathrm{O}_{3}$ grinding powder. 
activities that would be necessary to make a quantitative determination of the specific activities of iron and sulfur, were not available. 


\section{DISCUSSION Of RESULTS.}

It has been shown that the szilard-Chalmers separation on $\mathrm{C}_{12} \mathrm{FeCl}_{3}$ is successful to less than $1 \%$. As has been already suggested, this result does not appear too surprising when one considers the structure of the compound under discusslon. Above and below the planar ferric ion network there is a parallel triangular net plane of chloride lons, and above and below these planes of chloride lons there is a tightly bonded hexagonal plane of carbon atoms. This arrangement repeated through the lattice, serves to produce formidable steric hindrance effects for an atom of either iron or chlorine which might leave the lattice. This has been shown in tests for exchange between the $\mathrm{Fe}^{+++}$lons bound in the graphite lattice and $\mathrm{Fe}^{+++}$lons in surrounding solution. No measurable exchange was observed even after a four month period. The retention by the $\mathrm{C}_{12} \mathrm{FeCl}_{3}$, of over $99 \%$ of the activity developed by neutron irradiation may possibly also be explained by the pronounced steric effect. Recombination of "hot" fragments (in a so-called reaction cage) would appear to be quite probable in a solid material of this type. The separation of activity which does result from the szilardChalmers reaction (approx. $0.68 \%$ ), . cannot be explained on the basis of impurities in the $\mathrm{C}_{12} \mathrm{FeOl}_{3}$. It has been shown that the purified compound contained less than $4 \mu \cdot \mathrm{gm}$. Fe/gm. as free ferric chloride. This amount could only account for $0.3 \%$ of the fraction of activity that was separated, enen if it were all extractable following irradiation. 
one theory which might explain the small separation of activity, is that it is only the edge atoms in this "stacked layers" structure which are able to break away following neutron capture. This idea finds some support in the experiments. which showed. that griping the powdered compound to a finer size increased to some extent the fraction of activity separated. Thus the percentage Jield was raised from 0.684 to $0.737 \%$ presumably due to the breaking of the crystals and exposure of new edges from which irradiation freed active atoms were removed by the hydrochloric acid solution.

It would be of interest to subject samples of $\mathrm{C}_{12} \mathrm{FeCl}_{3}$ of different particle size to neutron irradiation and compare the szilard-Chalmers yield. Also there is the possibility that the irradiation of the compound for a shorter perlod or in a lower neutron flux might lead to a more successful separation of activity. Radiation experiments have shown that the estabIfshment of a successful Szilard-Chalmers enrichment reaction in experiments of low flux or short bombarament, does not ensure its success when longer or more intense bombardments are employed. It may be that in the case of $\mathrm{C}_{12} \mathrm{FeCl}_{3}$, some of the initially separated activity is lost by a radiationinduced back reaction. This situation does not seem too likely, since the separable form represents a less complicated breakdown product of the starting material. The siliardChalmers enrj.chment experiments with antimony pentafluoride (R.R. Wliliams (36)) however, show this loss of activity 
without apparent decomposition. The activity in the separable form aropped from 60 to $5 \%$ of the total after several hours bdmbardment at constant pile power. Nevertheless, it seems apparent that even under more suitabie conditions, a compound of the graphite ferric chloride type could not be expected to give any appreciable separation of activity by a szilardChalmers reaction. 
SUGGESTIONS fOr FURTHER RESEARCH.

1. It is probable that graphite ferric chloride and the other graphite compounds described represent only a few of the "stacked layer" structures which are capable of existance. Rlliorff has attempted the preparation of graphite compounds of $\mathrm{AsI}_{3}, \mathrm{SbI}_{3}, \mathrm{BII}_{3}, \mathrm{AsCl}_{3}, \mathrm{SbCl}_{3}, \mathrm{BiCl}_{3}, \mathrm{AICl}_{3}, \mathrm{COCl}_{3}$ and $\mathrm{CrCl}_{3}$, without result. (22) There is little doubt however, that further research wlll bring to light additional examples of molecules penetrating between the layer planes of the graphite lattice to form more or less stable structures.

2. The idea that it is only a few exposed edge atoms that are able to achieve bond rupture and subsequent ejection from the crystal lattice of $\mathrm{C}_{12} \mathrm{FeCl}_{3}$, could be investigated. The neutron irradiation of samples of different particle size. (different ratio of edge atoms to total atoms) might possibly lead to greater percentage yields of separated activity.

3. A further research concerning a study of radiation effects on graphite ferric chloride would be of interest. The correlation between flux intensity and period of bombardment and fraction of activity separable, could be ascertained. 


\section{BIBLIOGRAPHY.}

(1) Bernal, J.D., Proc. Roy• Soc. Acvi 749 (1924)

(2) Bragg, W.L., Proc. Roy. Soc. $\underline{489} 277$ (1913)

(3) Flagg, J.F., J.Am.Chem. Soc. 63 577 (1941)

(4) Fredenhagen, Cadenback, and Suck, $\mathrm{Z}$. anorg. allg. Chem.

$$
\begin{array}{lll}
158 & 249 & (1926) \\
178 & 353 & (1929)
\end{array}
$$

(5) Heyesy, G., and Paneth, F., Manual of Radioactivity, oxford Tiniversity Press, (1938)

Hahn, 0., Applied Radiochemistry, Cornell University Press, (1936)

(6) Hofman, U., Naturwissenshaften, $\underline{32} 260$ (1944)

(7) Hofman, U., and Frenzel, A., Z. Elektrochem.,

$$
\text { 40 } 511 \text { (1934) }
$$

(8) Hull, A.V!., Phy. Rev., $\underline{x} 661$ (1917)

(9) Juliusberger, F., Topley, B., and Weiss, J.,

$$
\text { J. Chem. Soc., p.1295 }
$$

(10) Laidler, D.S., and Taylor, A., Nature,

$$
\underline{146} \quad 130 \quad(1940)
$$

(11) Long, F.A., J.Am. Chem. Soc., 의 1353 (1941)

(12) Manguin, C., Bull. Soc. Franc. Min.,

$$
\text { XIIX } \quad 32 \quad \text { (1926) }
$$

(13) Medlin, w.V., J. Am. Chem. Soc., $57 \quad 1026$ (1935)

(14) Melander, L., Acta Chem. Scand., I 169 (1947)

(15) McKay, H.A.C., Nature, 142 (1938)

(16) ott, H., Ann. Physik., IXXXV(IV) 81 (1928)

(17) Pauling, L., The Nature of the Chemical Bond Cornell University Press, 2nd Edition,

(18) RileJ, H.I., Journ. Inst. Fuel, $\underline{X} .149$ (1937) 
(19) Riley, H.I., Fuel

(20) Ruben, S., Kamen, M.D., Allen, M.B., and Nahinsky, P. J. Am. Chem. Soc., $64 \quad 2297(1942)$

(2I) Rtldorff, w., Z. anorg. Chem. $\underline{245} 383$ (1941)

(22) Rtidorff, w., Field Information Agency, Technical(F.I.A.T) Review of German Sclence 1939-46 Inorganic chemistry, part I. 239

(23) Ridorff, W. and Hofmann, H., Z. anorg. Chem., $\underline{238} \quad 1$

(24) Rldorff, W., and Rldorff, G., Chem. Ber., $80 \quad 413(1947)$

(25) Rtldorff, W., and Schulz, H., $\mathrm{Z}$. anorg. Chem., $245 \quad 121$ (1940)

(26) Ruess, G.L., Monatsheften, 76 $\quad 381 \quad$ (1947)

(27) Ruff, 0., and Brettschnelder, 0.,

$$
\text { Z. anorg. Chem., } 217 \quad 1 \text { (1934) }
$$

(28) Schleede and Wellman,

$$
\text { Z. Physik, Chem. }
$$

XVIII 1 (1932)

(29) Seaborg, G.T., Chom. Rev., 27 $199(1940)$

(30) Stelgman, J., Phy. Rev., 59498 (1941)

(31) Stle, P., and Kayas, G., Jour. Chem. Phys.,

$45 \quad 188(1948)$

(32) Szllard, I., and chalmers, T.A.,

$$
\text { Nature, }
$$

$134 \quad 462$

(33) Thlele, H., Kollold-Z., $56 \quad 129$ (1931)

(34) Welcher, F.S., Organic Analytical Reagents, Vol.l (1947)

(35) Wilk, M.B., Canadian Journal of Research,

(36) Williams, R・R・, J. Phy• Coll. Chem., $\underline{52}$ $603(1948)$ 